\title{
Insular cortex corticotropin-releasing factor integrates stress signaling with social affective behavior
}

\author{
Nathaniel S. Rieger (iD ${ }^{1}$, Juan A. Varela ${ }^{1}$, Alexandra J. $\mathrm{Ng}^{1}$, Lauren Granata ${ }^{2}$, Anthony Djerdjaj ${ }^{1}$, Heather C. Brenhouse ${ }^{2}$ and \\ John P. Christianson (D) ${ }^{1 凶}$
}

(c) The Author(s) 2022

\begin{abstract}
Impairments in identifying and responding to the emotions of others manifest in a variety of psychopathologies. Therefore, elaborating the neurobiological mechanisms that underpin social responses to social emotions, or social affective behavior, is a translationally important goal. The insular cortex is consistently implicated in stress-related social and anxiety disorders, which are associated with diminished ability to make and use inferences about the emotions of others to guide behavior. We investigated how corticotropin-releasing factor (CRF), a neuromodulator evoked upon exposure to stressed conspecifics, influenced the insula. We hypothesized that social affective behavior requires CRF signaling in the insular cortex in order to detect stress in social interactions. In acute slices from male and female rats, CRF depolarized insular pyramidal neurons. In males, but not females, CRF suppressed presynaptic GABAergic inhibition leading to greater excitatory synaptic efficacy in a CRF receptor 1 (CRF $)_{1}$ - and cannabinoid receptor $1\left(\mathrm{CB}_{1}\right)$-dependent fashion. In males only, insular CRF increased social investigation, and $\mathrm{CRF}_{1}$ and $\mathrm{CB}_{1}$ antagonists interfered with social interactions with stressed conspecifics. To investigate the molecular and cellular basis for the effect of $C R F$ we examined insular $C_{2 R}$ and $C_{1} B_{1}$ mRNAs and found greater total insula $C_{1} F_{1} m_{R N A}$ in females but greater $C_{2} F_{1}$ and $\mathrm{CB}_{1}$ mRNA colocalization in male insular cortex glutamatergic neurons that suggest complex, sex-specific organization of CRF and endocannabinoid systems. Together these results reveal a new mechanism by which stress and affect contribute to social affective behavior.
\end{abstract}

Neuropsychopharmacology (2022) 47:1156-1168; https://doi.org/10.1038/s41386-022-01292-7

\section{INTRODUCTION}

Stressors and other salient emotional stimuli trigger a shift in attention and cognitive resources in order to orient attention and organize situationally adaptive behaviors. In the brain, the transition between resting and executive cognitive networks involves the insular cortex and the "salience network" [1, 2], which is anatomically situated to integrate sensory, emotional and cognitive processes [3, 4]. Not surprisingly, insula is associated with many cognitive functions and, in human neuroimaging studies, insula activity correlates with emotion recognition, pain, drug craving and anticipatory fear [5-8]. Specifically, the posterior insular cortex in rodents integrates external sensory cues with internal states and is interconnected with a number of subcortical regions to modulate behavior in response to these cues in a topdown fashion $[4,9,10]$. Aberrant activity and functional connectivity of the posterior insula and associated network structures leads to hypervigilance, increased interoception and poor emotion regulation-hallmark symptoms of many neuropsychiatric disorders including autism spectrum disorders, schizophrenia, and posttraumatic stress disorder [11].

Stress is a major precipitating factor for mental illness. Exposure to either a perceived threat to one's own well-being (self stress), or to a social contact that is undergoing distress initiate the hypothalamic-pituitary-adrenocortical axis response by activation of corticotropin-releasing factor (CRF) neurons in the paraventricular hypothalamus (PVN) [12]. The CRF system is complex, consisting of 2 receptor subtypes $\left(\mathrm{CRF}_{1}\right.$ and $\left.\mathrm{CRF}_{2}\right)$ that couple to a variety of $\mathrm{G}$-proteins expressed in the brain region, cell type, and sex-specific ways $[13,14]$. $\mathrm{CRF}_{1}$ and $\mathrm{CRF}_{2}$ receptors are distributed throughout brain social behavioral networks making CRF an important contributor to many social behaviors [15]. CRF receptors and CRF immunoreactive fibers are expressed throughout the corticolimbic system, including in the insular cortex [1619]. Observing others in distress is highly salient and a potent driver of insular activity that is thought to contribute to empathic cognition $[20,21]$. A fundamental precursor to empathy is emotion contagion, a primitive process by which the affective state of a demonstrator leads to a complementary state in the observer [22]. CRF neurons of the PVN are activated upon exposure to stressed conspecifics that is a mechanism providing for the social transfer of stress responses [12]. CRF may shape social behaviors by actions at CRF receptors located among the distributed network of neural structures, including the insular cortex, that are engaged by social stress signals and organize social behavior [23].

Seeing CRF as a putative modulator of insula and considering the significant influence of stress on psychosocial processes, we investigated the effects of CRF on insular physiology and social

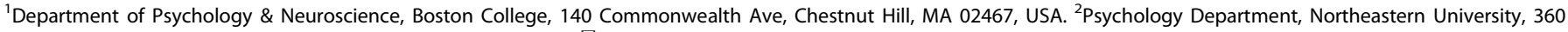
Huntington Avenue, 115 Richards Hall, Boston, MA 02115, USA. ${ }^{凶}$ email: j.christianson@bc.edu

Received: 1 November 2021 Revised: 10 January 2022 Accepted: 2 February 2022

Published online: 26 February 2022 
affective behavior. In whole-cell recordings of insular pyramidal neurons, CRF depolarized the membrane potential. This translated to an increase of excitatory synaptic transmission, but only in recordings from male rats. The gain of synaptic efficacy appeared to be a case of CRF causing depolarization-induced suppression of inhibition (DSI [24]) as the effects of CRF were dependent on both $G_{A B A_{A}}$ and cannabinoid type 1 receptor $\left(\mathrm{CB}_{1}\right)$. In social behavior, $\mathrm{CRF}$ augmented social investigation while a $\mathrm{CRF}_{1}$ antagonist interfered with social interactions with stressed conspecifics in male but not female rats. Because we observed sex-specific effects of CRF on physiology and behavior, we hypothesized that sex differences exist in $\mathrm{CRF}_{1}$ and $\mathrm{CB}_{1}$ at the cellular and molecular levels. We employed a combination of quantitative polymerase chain reaction (qPCR) and anatomical (in situ hybridization) analyses and found sex differences in $\mathrm{CRF}_{1}$ mRNA expression and differences in the cellular distribution of the transcripts in the insular cortex. Together, the data lead us to conclude that CRF, acting upon $\mathrm{CRF}_{1}$ receptors depolarizes pyramidal neurons triggering the release of endocannabinoids which suppress presynaptic inhibition. The result facilitated flow of information through the insula that appears to be necessary for coordinating social interactions with stressed conspecifics.

\section{MATERIALS AND METHODS}

For a complete description of the experimental methods please refer to the Supplementary Materials.

\section{Animals}

Male and Female Sprague-Dawley rats were obtained from Charles River Laboratories (Wilmington, MA) at either age PN45 (test rats and adult conspecifics) or PN21 (juvenile conspecifics) and maintained in the same-sex groups of two to three. All procedures were conducted in accordance with the $\mathrm{NIH}$ Guide for the care and use of laboratory animals and approved by the Boston College Institutional Animal Care and Use Committee.

\section{Electrophysiology}

Whole-cell and extracellular field potential recordings were obtained from acute insular cortex slices from adult male and female rats with methods reported previously [21]. Active and passive intrinsic membrane properties were determined with current clamp recordings with the glutamatergic receptor blocker kynurenic acid $(1 \mathrm{mM})$ and the $\mathrm{GABA}_{\mathrm{A}}$ receptor antagonist SR95531 $(2 \mu \mathrm{M})$ in the recording aCSF to block synaptic transmission. After achieving a whole-cell configuration, baseline recordings were made in aCSF until $10 \mathrm{~min}$ of stable baseline were observed, at which point $50 \mathrm{nM}$ CRF (human/rat, Cat. No 1151, Tocris) was added to the bath. The dose of $50 \mathrm{nM}$ was selected after a pilot study using a range of doses from 50 to $300 \mathrm{nM}$, representative of the low [25] and high [26] doses found in the literature. While dose responses were evident in field recordings, no dose responses were seen in intrinsic measures between 50 and $300 \mathrm{nM}$ concentrations. Therefore, patch-clamp experiments utilized $50 \mathrm{nM}$ CRF.

Evoked field excitatory postsynaptic potentials (fEPSPs) were recorded on a perforated multielectrode array. CRF (50 or $300 \mathrm{nM}$ ), $\mathrm{CRF}_{1}$ antagonist CP154526 $(10 \mu \mathrm{M}$, the dose that prevented CRF effects on intrinsic properties and comparable to other studies [26]), and $\mathrm{GABA}_{A}$ inhibitor SR95531 ( $2 \mu \mathrm{M}$, a dose that eliminates spontaneous and evoked IPSCs in our preparation, Varela JA and Christianson JP, unpublished data) were dissolved in water or DMSO and then diluted to their final concentration in aCSF and bath applied. Input/output curves were established at baseline (aCSF) and again after $10 \mathrm{~min}$ of drug application. Stimulations ranged from 0 to $5 \mathrm{~V}$ and occurred in biphasic $(220 \mu \mathrm{s}) 500 \mathrm{mV}$ increments.

To determine the effect of CRF on $G A B A_{A}$-mediated evoked inhibitory postsynaptic currents (elPSCs), synaptic responses were evoked by a bipolar extracellular stimulating electrode in the presence of glutamatergic antagonists during voltage-clamp recordings of insular pyramidal neurons. eIPSCs were quantified as the peak amplitude observed in the $1 \mathrm{~ms}$ post stimulation and converted to z-scores using the mean and standard deviation of the baseline (aCSF).

\section{Surgical implantation of insula cannula and microinjection}

Bilateral guide cannula was implanted in the posterior insular cortex. The posterior insula was targeted because it is functionally connected to the social decision-making network $[10,27]$, necessary to social affective processing $[28,29]$ and contains $m R N A$ for $\operatorname{CRF}_{1}$ receptor [17, 30, 31]. For insula microinjections, CRF was dissolved in DI water and diluted to $300 \mathrm{nM}$ concentration in a vehicle of $0.9 \%$ saline. $\mathrm{CRF}_{1}$ receptor antagonist $\mathrm{CP} 154526$ (Sigma) and $\mathrm{CB}_{1}$ receptor inverse agonist $\mathrm{AM} 251$ (Tocris) were dissolved in DMSO then diluted to 10 or $2 \mu \mathrm{M}$, respectively, in a vehicle of $10 \%$ DMSO and $0.9 \%$ saline.

\section{Social exploration}

One-on-one social interaction tests were completed in a quiet room as previously described $[29,32]$. The test began with the introduction of either a juvenile ( $28 \pm 2$ days old) or adult ( $50 \pm 2$ days old) same-sex conspecific. Rats were then allowed to interact for $5 \mathrm{~min}$ and interactions were scored for social behaviors (sniffing, pinning and allogrooming) initiated by the test rat by an observer blind to treatment. Rats were tested on consecutive days. For CRF testing, rats received either vehicle or CRF in a counterbalanced order. For $\mathrm{CRF}_{1}$ antagonist and AM251 experiments, rats received 4 treatments (vehicle, $C R F, C R F_{1}$ antagonist, or $C R F+C_{1} F_{1}$ antagonist) or (vehicle, CRF, AM251, CRF + AM251), respectively, on consecutive days with treatment order counterbalanced in a Latin square design.

\section{Social affective preference (SAP) test}

The SAP tests allow for the quantification of social interactions initiated by a test rat toward either a stressed or unstressed conspecific, providing insight into the test animal's discrimination of socioemotional affective cues; they were conducted exactly as previously described [29, 32, 33]. Briefly, the SAP test begins when a test rat is placed in the center of an arena containing chambers on opposite sides containing conspecifics. The test rat was allowed to interact with the conspecifics for $5 \mathrm{~min}$ and time spent body sniffing and reaching for the conspecific was recorded. Microinjections were made 30-40 min prior to tests in which one of the conspecifics placed into the cage was stressed via two, $5 \mathrm{~s} 1 \mathrm{~mA}$ footshocks (60 s interval) immediately before testing and the other conspecific was naive to stress. Microninjections consisted of either vehicle, $\mathrm{CRF}_{1}$ antagonist or $\mathrm{CB}_{1}$ antagonist as described above in a counterbalanced, within-subject design.

\section{Insular mRNA quantification}

To determine the relative expression of $\mathrm{CRF}_{1}$ (crhr1), $\mathrm{CB}_{1}$ (cnr1) CRF (crh), and $\mathrm{CRF}_{2}$ (crhr2) mRNA we performed quantitative Taq-man reverse transcriptase qPCR analysis on $1 \mathrm{~mm}$ dia, $\sim 500-\mu \mathrm{m}$ thick insular cortex punches, as previously described [34].

\section{RNAScope in situ fluorescent hybridization}

RNAScope was performed on insular cortex sections according to the vendor's instructions (ACDBio). Briefly, tissue was thawed, fixed and treated with a RNAScope cocktail including probes for $\mathrm{CRF}_{1}$ (crhrl, catalog \#318911), CB 1 (cb1, catalog \#412501), vesicular glutamate transporter 1 (vglut1, catalog \#317001) and DAPI. The total number of nuclei (DAPI) and glutamate cells (Vglut+DAPI), and cells colocalized with $\mathrm{CRF}_{1}, \mathrm{CB}_{1}$ or both were determined. Effects of sex on cell counts were assessed in two-way ANOVAs with sex as a between-group factor and side as a within-subject factor. The mean of left and right hemisphere counts are shown.

\section{Statistics}

All analyses were performed in Prism (GraphPad, version 9.0.2) and results of analysis of variance, $t$-tests, final sample size and post hoc test results are presented in the figure legends.

\section{RESULTS}

\section{Corticotropin-releasing factor depolarizes insular cortex} pyramidal neurons

Active and passive intrinsic properties (Supplementary Table 1) were computed from insular pyramidal neurons before and after the application of CRF (50 nM). Each parameter was analyzed for sex differences, CRF effects and sex by CRF interactions. With regard to sex differences in intrinsic properties, male and female intrinsic properties under aCSF recording conditions were comparable; no main effects of sex were present for any 
A

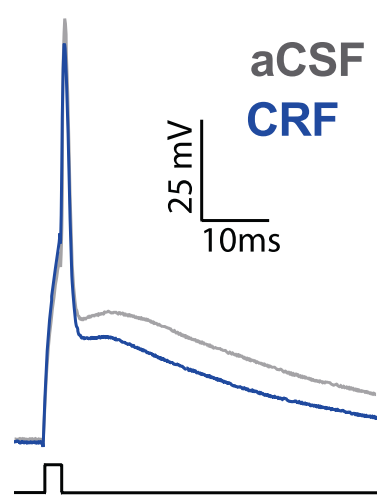

D

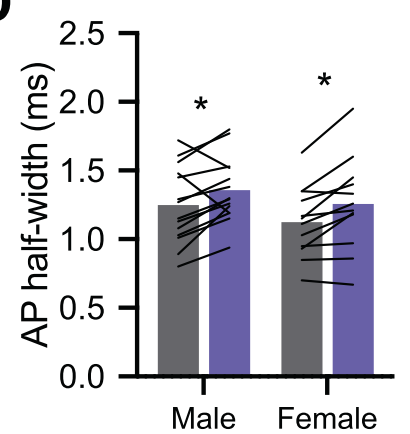

B

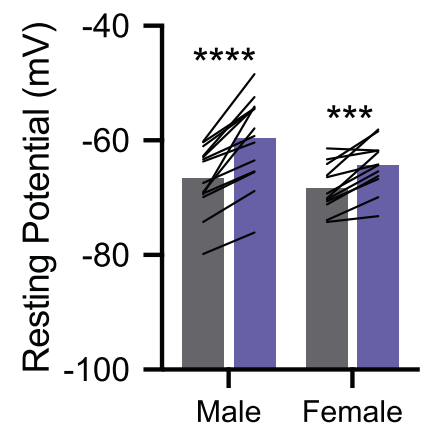

$\mathbf{E}$

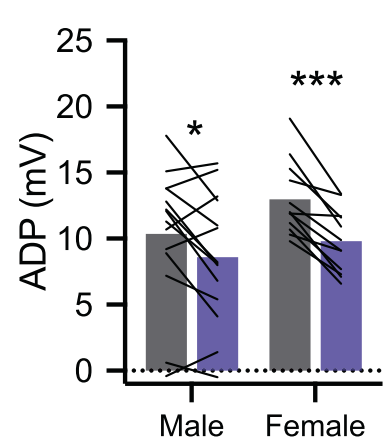

C

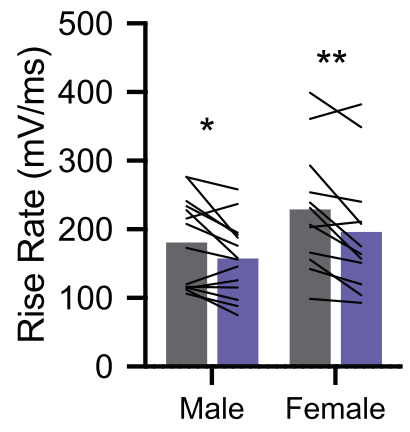

$\mathbf{F}$

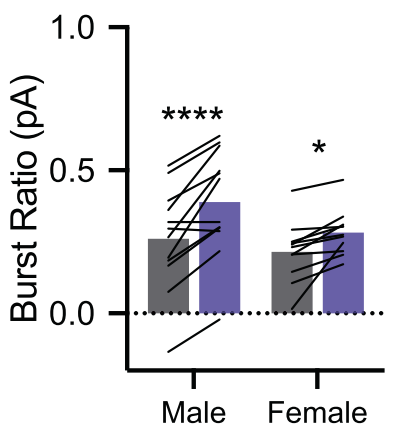

G

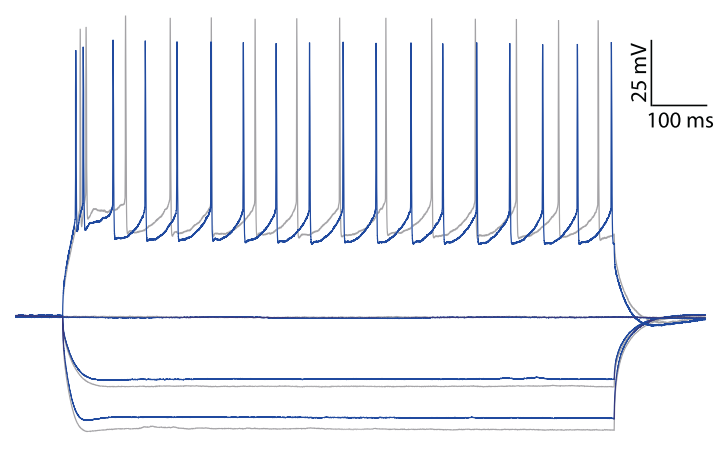

H

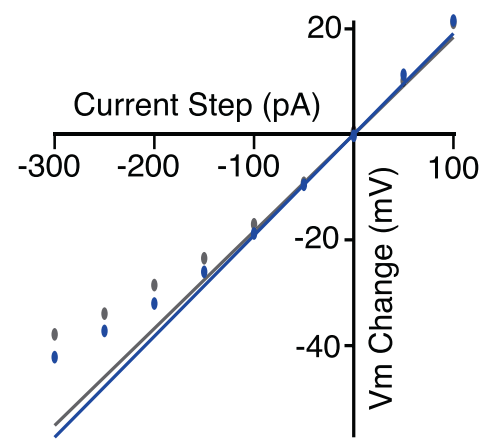

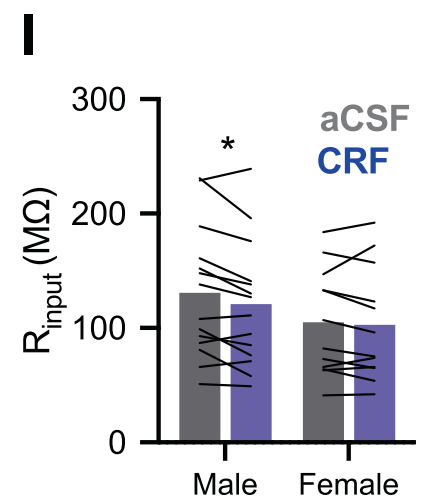

$J$

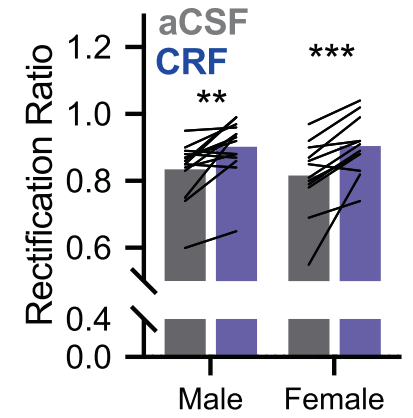

K

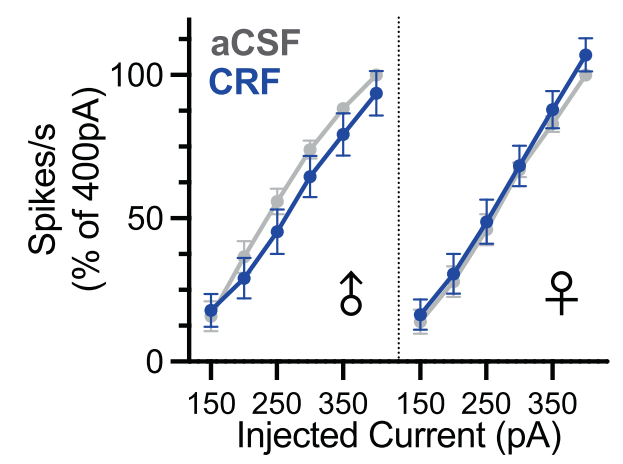

parameter. CRF altered many intrinsic properties including depolarization of resting membrane potential (Fig. 1A), reduction in action potential (AP) amplitude and rise rate (Fig. 1B), and corresponding increase in AP half-width (Fig. 1C). Many insular cortex pyramidal neurons have a bursting phenotype [29] and CRF appeared to reduce after depolarization (ADP) amplitude (Fig. 1D) and increased the current required to elicit a burst (burst ratio, Fig. 1E). CRF reduced firing rate (Table 1) consistent with CRF effects in the hippocampus [35]. A few sex-specific effects of CRF emerged in the passive properties. In males, CRF reduced input 
Fig. 1 CRF alters intrinsic properties of male and female insular cortex pyramidal neurons in whole-cell recordings. A Representative single action potential (AP) recordings of deep layer insular cortex pyramidal neurons at baseline (aCSF-gray) and after application of $50 \mathrm{nM}$ Corticotropin-releasing factor (CRF-blue). B CRF decreased the resting potential of male $(n=14)$ and female $(n=12)$ pyramidal neurons, $F_{\mathrm{CRF}}(1,24)=72.93, P<0.0001$, with this effect being stronger in males than females as indicated by a CRF $\times$ sex interaction, $F_{\mathrm{CRF}} \times \mathrm{SEX}(1,24)=$ $5.124, P=0.033$. C Action potential rise rate was reduced by CRF in both males and females, $F_{\mathrm{CRF}}(1,24)=18.93, P=0.0002$. D Action potential half-width increased following CRF application in male and female recordings, $F_{C R F}(1,24)=16.69, P=0.0004$. $E$ CRF reduced the amplitude of the after depolarization (ADP) in both male and female recordings, $F_{\mathrm{CRF}}(1,24)=26.83, P<0.0001$. $F$ CRF increased the current required to trigger burst firing in male and female neurons, $F_{\mathrm{CRF}}(1,24)=38.82, P<0.0001$. G Representative family of $1 \mathrm{~s}$ hyperpolarizing and depolarizing current injections used characterize passive membrane properties and spike rate in aCSF (gray) and after $50 \mathrm{nM} \mathrm{CRF} \mathrm{(blue).} \mathbf{H}$ Example steadystate current-voltage dependence plot. Input resistance was determined by linear fit and slope at OpA and deviation from fit indicates rectification. I CRF reduced membrane input resistance in male and female neurons, $F_{\mathrm{CRF}}(1,24)=5.985, P=0.022$; this effect appeared most robustly in males. J CRF increased rectification of membrane potential in males and females, $F_{\mathrm{CRF}}(1,24)=35.28, P<0.0001$. $\mathbf{K}$ CRF did not alter firing rates in response to $1 \mathrm{~s}$ depolarizing current injections in either males or females. Bar graphs indicate mean with individual replicates, line graphs mean $\left( \pm\right.$ SEM). ${ }^{*} P<0.05,{ }^{* *} P<0.01,{ }^{* *} P<0.001,{ }^{* * *} P<0.0001$ (Sidak's tests).

resistance (Fig. 1F) and in females, CRF reduced the membrane time constant. Interestingly, CRF increased the rectification ratio (Fig. 1G) to a similar extent in males and females. These results are not likely the result of diffusion or cell dialysis effects during recordings because under identical circumstances and recording times, these parameters are stable [29]. To establish whether the effects of CRF on insular cortex pyramidal neurons were mediated by action at the $\mathrm{CRF}_{1}$ receptor, which is the primary CRF receptor in insula [16, 17], we replicated the intrinsic characterization (Supplementary Fig. 1). For each parameter that was significantly changed by CRF in the first experiment, the $\mathrm{CRF}_{1}$ antagonist appeared to prevent those changes suggesting that the $\mathrm{CRF}_{1}$ receptor is the primary target of CRF in the insular cortex.

\section{CRF augments excitatory neurotransmission in the insula}

The effects of CRF on intrinsic properties suggest a mix of augmentation (depolarization) and dampening (reduced AP parameters, reduced bursting) modulation. To better understand how CRF might alter insular cortex information throughput, we investigated CRF effects on synaptic transmission (Fig. 2A). fEPSP input/output curves were generated in aCSF and then again in either 50 or $300 \mathrm{nM}$ CRF from stimulation within the insular cortex. In male, but not female, slices, CRF caused a dose-dependent leftward shift indicating augmented synaptic efficacy at both 50 nM (Fig. 2B) and 300 nM (Fig. 2C, D). We then tested whether CRF augmented insular synaptic excitability in males is $\mathrm{CRF}_{1}$ dependent by coapplying $300 \mathrm{nM}$ CRF and $10 \mu \mathrm{M}$ CP154526 during I/O curves. The $\mathrm{CRF}_{1}$ antagonist blocked the effects of CRF on fEPSP (Fig. 2E). In summary, CRF application increased excitatory synaptic efficacy in the insula of male rats via action at the $\mathrm{CRF}_{1}$ receptor.

\section{CRF reduces evoked presynaptic GABA release}

An enhancement of fEPSP transmission by CRF could result from direct augmentation of glutamatergic transmission or from inhibitory modulation of GABAergic transmission. Because CRF depolarized principle glutamatergic neurons we first tested whether CRF application would augment glutamatergic transmission by recording spontaneous EPSCs and AMPA and NMDA mediated currents before and after CRF ( $50 \mathrm{nM})$. Surprisingly, CRF had no effect on either measure or the AMPA/NMDA ratio (Supplementary Fig. 2). Therefore, we hypothesized that the enhancement of fEPSP observed after CRF was dependent upon $G A B A_{A}$. We tested this by pretreating male insular slices with $\mathrm{GABA}_{\mathrm{A}}$ antagonist SR95531 (2 $\left.\mu \mathrm{M}\right)$ and then applied CRF (300 nM) and repeated fEPSP input/output characterization. In the presence of the $G_{A B A}$ antagonist, CRF had no apparent effect (Fig. 2F). The same pattern was observed when using picrotoxin, a naturally occurring $\mathrm{GABA}_{\mathrm{A}}$ antagonist (data not shown). In a direct comparison, we found both $C_{R F}$ antagonist and the $G A B A_{A}$ antagonist blocked CRF based increases in insular excitatory synaptic transmission (Fig. 2G).
Because it is possible that CRF acts directly on GABAergic neurons in addition to its effects on principle neurons, we next used whole-cell, voltage-clamp recordings to investigate the effect of CRF on elPSCs (Fig. 2H). Here, CRF caused a marked reduction in eIPSC amplitude in males (Fig. 2l) but the effect was not present in females (Fig. 2J). Furthermore, pretreatment with the $\mathrm{CRF}_{1}$ antagonist eliminated the inhibitory effect of CRF on elPSCs in males (Fig. 2K). In a separate experiment, we examined spontaneous IPSCs and found reduced IPSC frequency, a trend consistent with CRF negatively modulating GABAergic tone (Supplementary Fig. 2).

\section{Insular CRF increases social exploration of conspecifics in males but not females}

The foregoing physiological findings suggest that CRF augments synaptic transmission in IC via downregulation of local GABAergic interneurons. Manipulations that alter insular excitability are associated with changes in social affective behaviors $[29,32,36,37]$ and the CRF system is implicated in many aspects of social behavior [15]. To begin to assess whether the effect of CRF in the slices was behaviorally relevant, we utilized social interaction behavior tests. We first investigated whether CRF influenced social investigation toward juvenile (P28) or adult (P50) conspecifics in male rats in a 5-min social investigation test (Fig. 3A). Bilateral infusion of either $50 \mathrm{nM} \mathrm{(238} \mathrm{pg/}$ $500 \mathrm{~nL})$ or $300 \mathrm{nM}(1.4 \mathrm{ng} / 500 \mathrm{~nL})$ doses of CRF to the insula of males led to an increase in the social investigation of both juvenile (Fig. 3B) and adult (Fig. 3C) conspecifics compared to social investigations following saline injections. To establish whether the sex difference observed in physiology was present in social behavior, a separate cohort of female rats received social interaction tests with juveniles following a $300 \mathrm{nM}$ injection of CRF. This dose was chosen because it showed a robust effect in male slices while female slices showed no response to either 50 or $300 \mathrm{nM}$ doses. Consistent with physiology, CRF did not alter female social interaction (Fig. 3D).

Next, we tested whether augmentation of male social interaction by CRF was $\mathrm{CRF}_{1}$ receptor dependent. As above, CRF increased social interaction compared to saline or CP154526, which was without effect (Fig. 3E, F). Importantly, social interaction levels did not differ from saline control levels when CRF was coadministered with CP154526 showing that CRFs augmentation of social behavior relies on $\mathrm{CRF}_{1}$ receptor activation in the insula.

\section{Social investigation of stressed conspecifics requires insular CRF $_{1}$}

The previous gain-of-function results provide evidence that insular $\mathrm{CRF}$ and $\mathrm{CRF}_{1}$ may contribute to social behavior. In a seminal study, Sterley et al. [12] demonstrated in mice that the CRF system is engaged during social encounters with stressed conspecifics. Similarly, we demonstrated that insula activity determines the nature of social interaction with stressed conspecifics, either approach or avoidance, in a SAP test $[29,32]$. We predicted that, in male rats, exposure to a stressed conspecific would evoke insular 
ڤึ

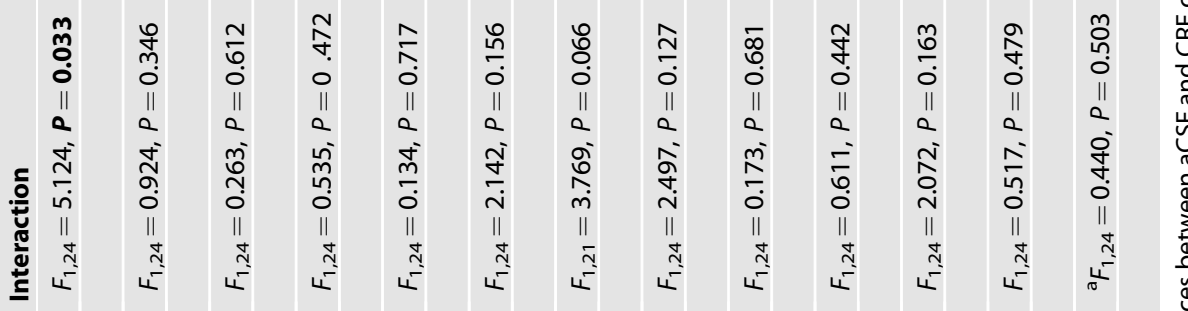

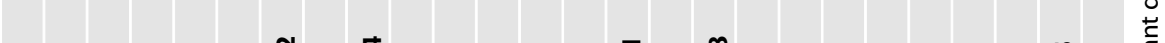

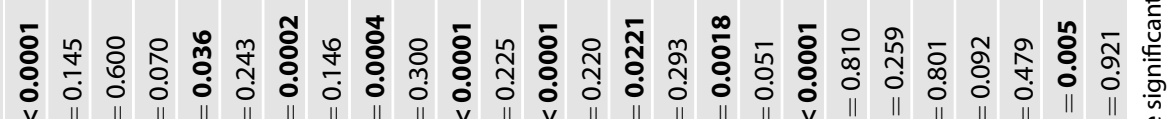
v

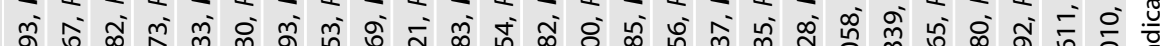

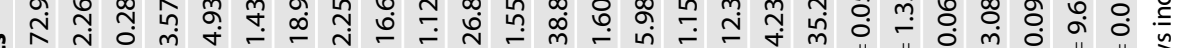

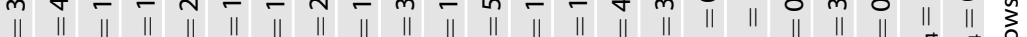
召 收 L 范岕

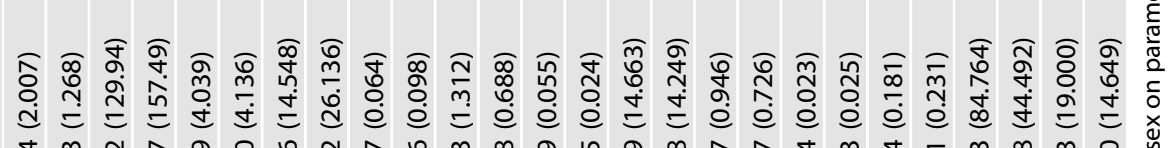

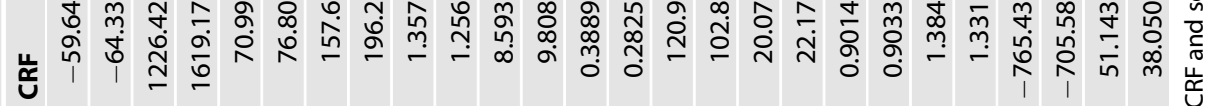

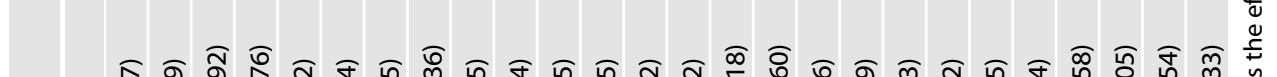

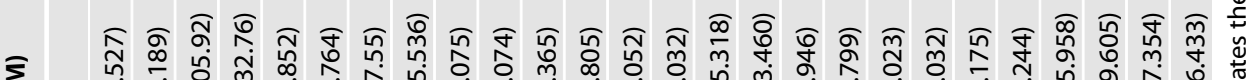

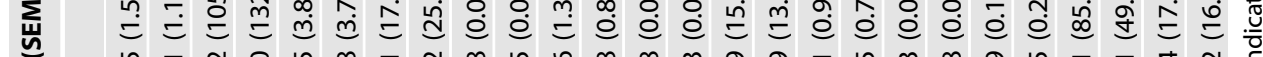

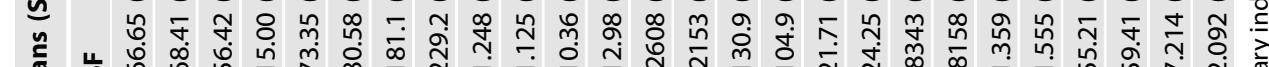
ర্ं

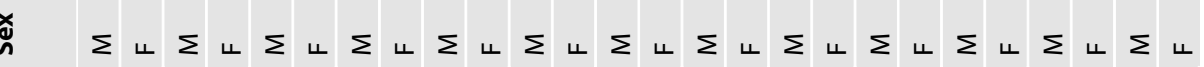

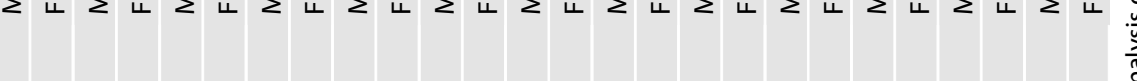

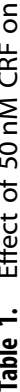

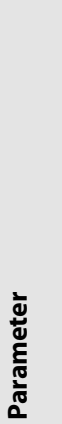

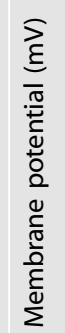

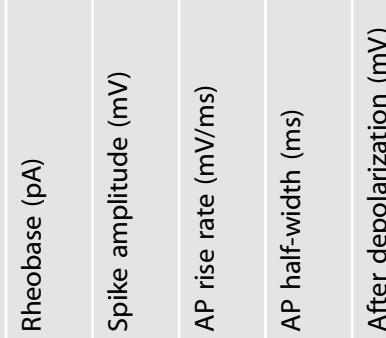

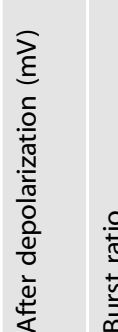

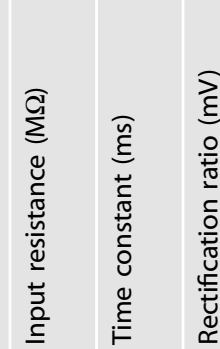

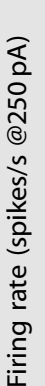

के

(1) 
A

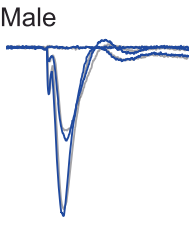

Female
B

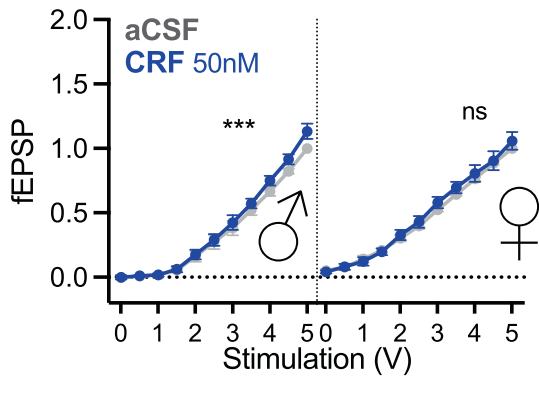

C

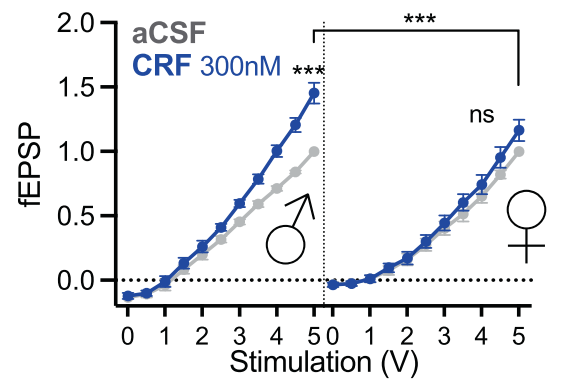

$\mathbf{F}$

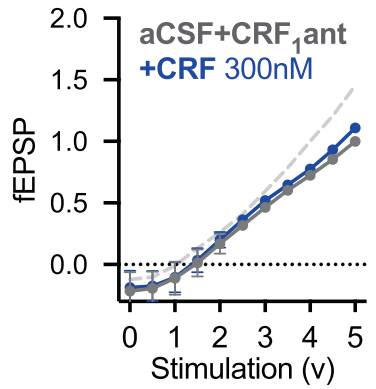

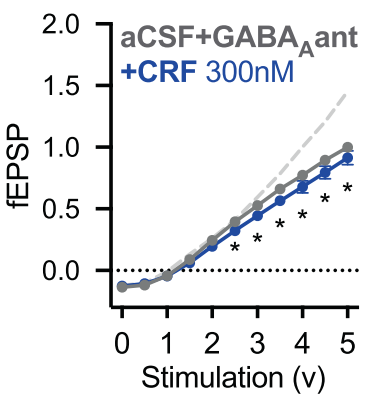

G

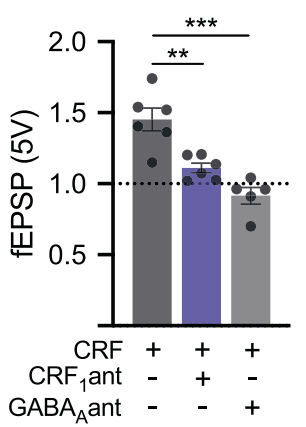

H

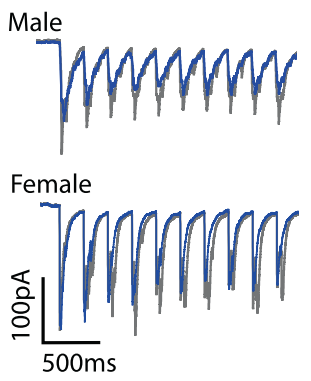

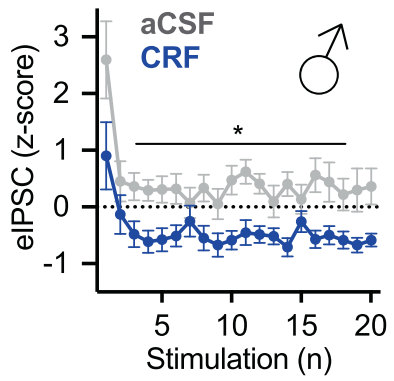

J

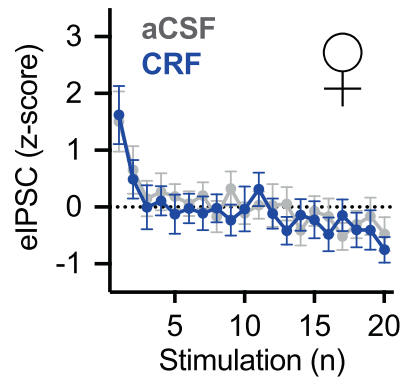

K

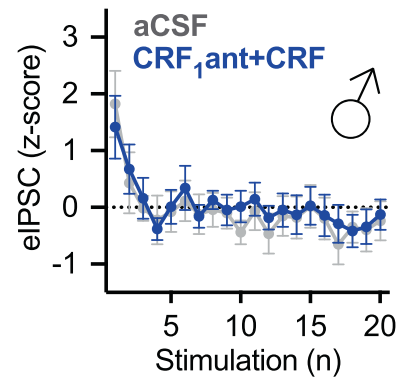

Fig. 2 CRF has dose- and sex-dependent synaptic effects in insular cortex slices. A Representative traces of male (above) and female (below) field excitatory postsynaptic potentials (fEPSP) at 1, 3 and $5 \mathrm{~V}$ under aCSF (gray) and after $50 \mathrm{nM}$ (left, blue) or $300 \mathrm{nM}$ CRF (right, blue) conditions. For analysis, traces were normalized to the peak amplitude of the fEPSP evoked at $5 \mathrm{~V}$ in aCSF. B Bath application of $50 \mathrm{nM}$ CRF significantly increased fEPSPs in male insular cortex slices in biphasic $0-5 \mathrm{~V}$ I/O curves $F_{\text {Voltage }} \times$ CRF $(20,80)=5.791, P<0.0001$ with post hoc tests showing CRF being significantly increased over baseline at $3 \mathrm{~V}(P=0.0425), 3.5 \mathrm{~V}(P<0.0001), 4 \mathrm{~V}(P=0.0001), 4.5 \mathrm{~V}(P=0.0091)$ and $5 \mathrm{~V}$ $(P=0.0009)$. However, there was no significant effect of CRF on female slices $F_{\text {Voltage } \times \text { CRF }}(20,80)=0.5351, P<0.5667$. A three-way ANOVA revealed significant interactions between voltage and CRF and sex: $F_{\text {Voltage }} \times \operatorname{CRF}(10,80)=3.654, P=0.0005, F_{\text {Voltage }} \times \operatorname{Sex}(10,80)=2.910, P=$ 0.0037 as well as a main effect of sex, $F_{\text {Sex }}(1,8)=10.53, P=0.0118$. C Bath application of $300 \mathrm{nM}$ CRF led to a sex difference in $\mathrm{fEPSPs}$ such that males showed increased synaptic efficacy but not females resulting in a significant three-way interaction, $F_{\text {Voltage }} \times$ Sex $\times$ CRF $(10,100)=5.306$, $P<0.0001$. Males showed significant increases in fEPSP under CRF conditions via Tukey's multiple comparison tests at $2.5 \mathrm{~V}(P=0.0370), 3 \mathrm{~V}$ $(P=0.0212), 3.5 \mathrm{~V}(P=0.0124), 4 \mathrm{~V}(P=0.0063), 4.5 \mathrm{~V}(0.0040)$ and $5 \mathrm{~V}(P=0.0058)$. D Comparing $5 \mathrm{~V}$ responses (normalized to female aCSF $5 \mathrm{~V})$ under $50 \mathrm{nM}$ versus $300 \mathrm{nM}$ CRF by sex revealed main effects of $\operatorname{sex}, F_{\mathrm{Sex}}(1,18)=5.737, P=0.0277$, and $\mathrm{CRF}, F_{\mathrm{CRF}}(1,18)=7.855, P=0.0118$. Sidak's post hoc tests showed that there was a significant dose effect in males $t(18)=2.981, P=0.0471$, but not in females $t(18)=0.9826, P=$ 0.9165. E CRF 1 antagonist CP154526 $(10 \mu \mathrm{m})$ coapplied with $300 \mathrm{nM}$ CRF prevented CRF from increasing fEPSPs in slices from male rats. The dashed gray line depicts the effect of $300 \mathrm{nM} C R F$ alone for comparison. While there was a significant interaction $F_{\mathrm{V} \text { oltage }} \times \mathrm{CRF}(20,89)=3.276$, $P<0.0001$. There was no main effect of $\operatorname{CRF}, F_{\mathrm{CRF}}(2,10)=0.0362, P=0.9646$. No post hoc comparisons were significant across treatments at different voltages. $\mathbf{F}$ Coapplication of the GABA antagonist SR95531 prevented the enhancing effect of $300 \mathrm{nM}$ CRF and led to a significant decrease in fEPSPs $F_{\text {Voltage } \times \text { CRF }}(10,40)=3.464, P=0.0024$ in slices from male rats. Significant Tukey's post hoc comparisons were found at 2.5 $\mathrm{V}(P=0.0422), 3 \mathrm{~V}(P=0.0144), 3.5 \mathrm{~V}(P=0.0038), 4 \mathrm{~V}(P=0.0026), 4.5 \mathrm{~V}(P=0.0014)$, and $5 \mathrm{~V}(P=0.0116)$. G $5 \mathrm{~V} \mathrm{fEPSPs}$ after CRF, CRF + $\mathrm{CP} 154526$ and $\mathrm{CRF}+\mathrm{SR95531}(300 \mathrm{nM})$ were normalized to the relative $5 \mathrm{~V}$ fEPSP in aCSF in (D) to summarize the effect of CRF 1 and $\mathrm{GABA}_{\mathrm{A}}$

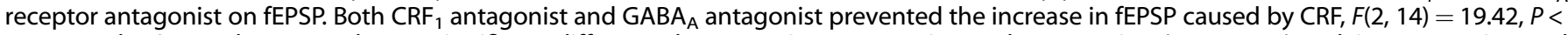
0.0001 . Tukey's post hoc tests show a significant difference between CP154526 + CRF and $300 \mathrm{nM}$ CRF $(P=0.0031)$ and SR95531 + CRF and $300 \mathrm{nM}$ CRF $(P<0.0001)$. H Voltage-clamp recordings of evoked inhibitory postsynaptic currents (elPSC) from deep layer insular cortex pyramidal neurons under baseline (gray-aCSF with glutamatergic synaptic antagonists) and after $50 \mathrm{nM}$ CRF (blue) in slices from male or female rats. Twenty elPSCs were evoked by extracellular bipolar electrodes at $5 \mathrm{~Hz}$ (the first 10 are shown). For analysis, elPSC amplitudes were normalized using z-scores computed from the mean and standard deviation of the aCSF recordings (panels I, J). Basal elPSC amplitudes did not differ between male and female recordings. I CRF significantly reduced the amplitude of elPSCs in males, $F_{\mathrm{CRF}}(1,8)=7.006, P=0.0294$. $J$

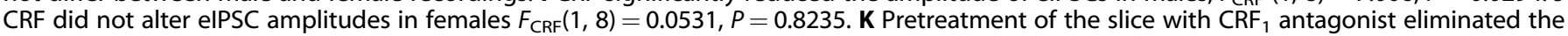
effect of CRF on elPSCs in slices from male rats, $F_{\mathrm{CRF}}(1,7)=0.0547, P=0.8218$. 
A

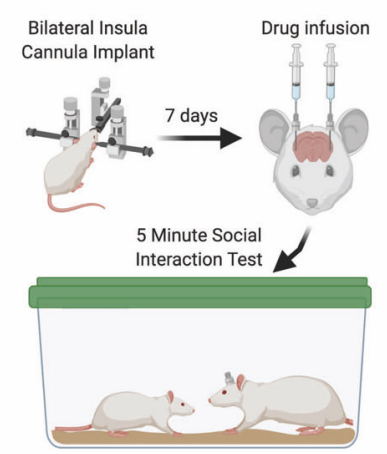

D

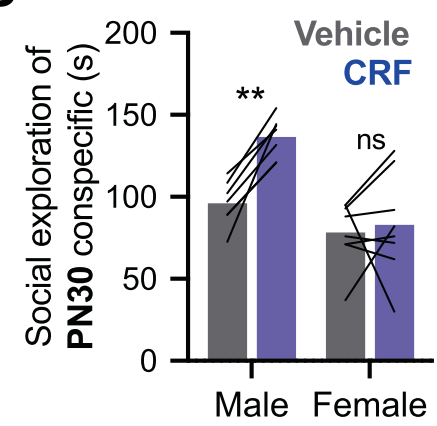

G

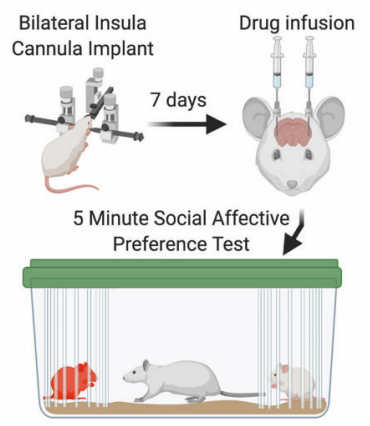

$J$

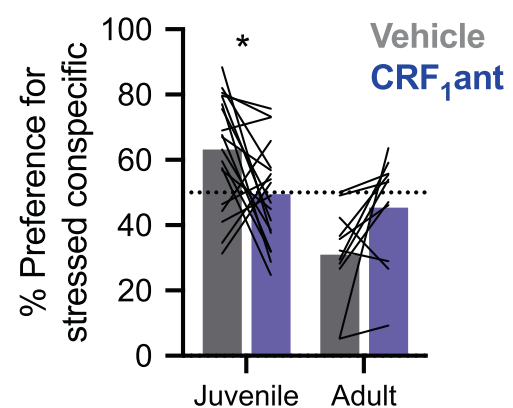

B

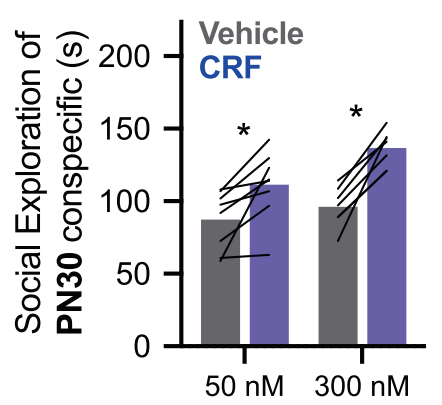

$\mathbf{E}$

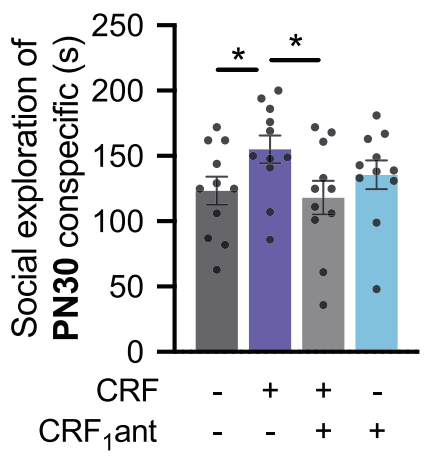

H

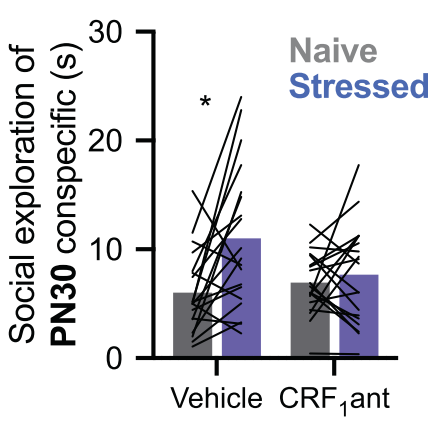

C

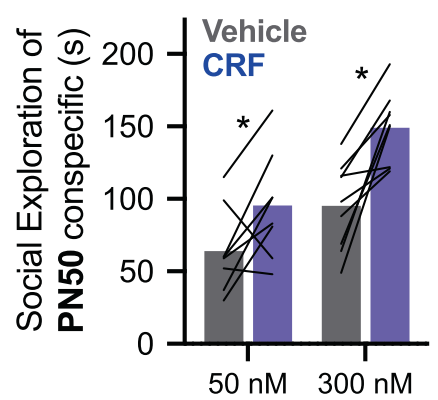

$\mathbf{F}$

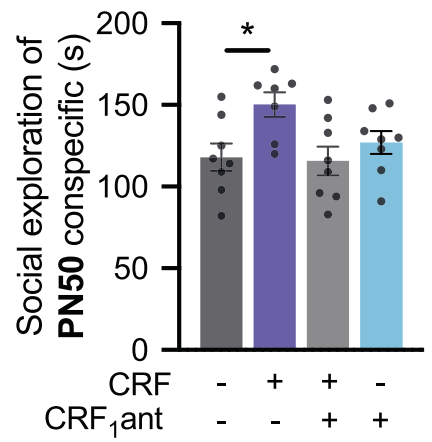

K

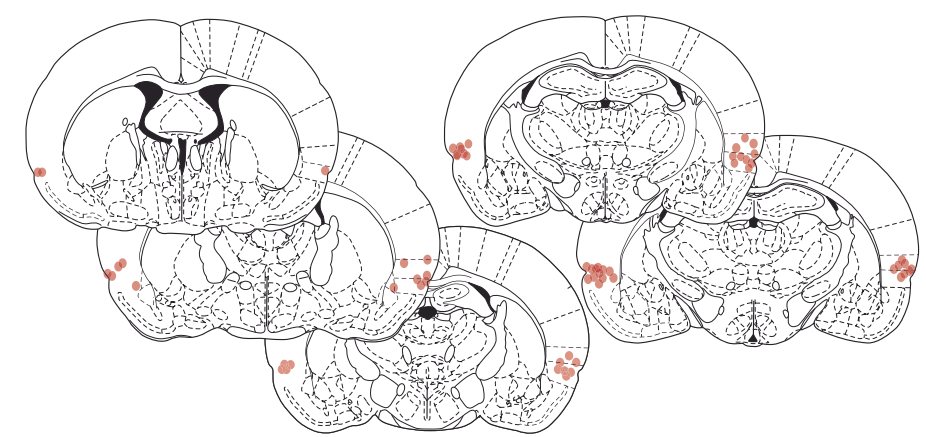

cortex CRF release that, via $\mathrm{CRF}_{1}$ may contribute to social affective behavior (Fig. 3G). CRF 1 blockade prevented the formation of a preference for stressed juveniles (Fig. $3 \mathrm{H}$ ) such that approach behavior did not differ toward stressed or unstressed conspecifics. After vehicle injections, rats displayed a preference for unstressed adult conspecifics but this preference was eliminated via injection of $\mathrm{CRF}_{1}$ antagonist (Fig. 3l). Percent preference for stressed individuals was significantly altered by $\mathrm{CRF}_{1}$ antagonist injections such that test rats lost preference for both stressed juveniles and non-stressed adults (Fig. 3J). To test whether CRF contributes to non-social emotional states associated with threat and are mediated by posterior insula [9] we injected CRF to the insula in rats during threat learning or threat recall in a Pavlovian conditioning procedure that results in an insula-dependent 
Fig. 3 CRF augments social behavior and is necessary for social affective behavior. A A diagram laying out the experimental procedure for social exploration tests. Cannula was placed in the insular cortex. On the day of testing, rats were given $1 \mathrm{~h}$ to acclimate to the testing cage. CRF or saline vehicle infusions were made $40 \mathrm{~min}$ prior to social interaction with a juvenile (P30) or adult (P50) conspecific for 5 min. B In male rats, CRF increased social exploration of juvenile conspecifics, $F_{\mathrm{CRF}}(1,13)=48.5, P<0.0001$. Sidak's post hoc tests revealed significantly increased social exploration at both $50 \mathrm{nM}(P=0.0044)$ and $300 \mathrm{nM}(P<0.0001)$. C In male rats, CRF also increased social exploration of P50 conspecifics, $F_{\mathrm{CRF}}(1,15)=24.99, P=0.0002$. Sidak's post hoc tests showed that social exploration was increased at both $50 \mathrm{nM}(P=0.0450)$ and $300 \mathrm{nM}(P=0.0007)$ doses. $\mathrm{D}$ In female rats, $300 \mathrm{nM}$ CRF did not alter social interaction with juvenile conspecifics. Female data were compared males at $300 \mathrm{nM}$ (data replotted from panel B to facilitate comparison) revealing a sex-specific effect of CRF $F_{\text {Sex }} \times$ CRF $(1,13)=6.517, P=$ 0.0241 such that males showed increased social exploration following CRF treatment $(P=0.0033)$ but females did not $(P=0.8615)$. E Social

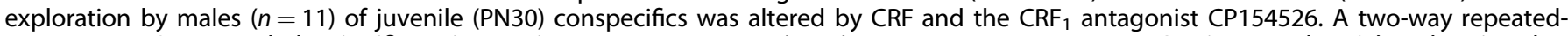
measures ANOVA revealed a significant interaction $F_{\mathrm{CRF}} \times \mathrm{CRF}_{\text {antagonist }}(1,10)=12.82, P=0.005 .300 \mathrm{nM}$ CRF increased social exploration that was significantly greater than both the vehicle condition (Tukey's post hoc test, $P=0.0359$ ) and the combined CRF and CRF 1 antagonist condition $(P=0.0152)$. Independently, the $\mathrm{CRF}_{1}$ antagonist had no effect on social exploration $(P=0.6093)$. $\mathbf{F}$ In tests of male rats $(n=8)$ with adult conspecifics, $\mathrm{CRF}_{1}$ antagonist blocked the increase in social interaction caused by $\mathrm{CRF}, F_{\mathrm{CRF}} \times \mathrm{CRF}_{\text {antagonist }}(1,6)=12.67, P=0.0119$. Mean social interaction time was greatest in the group that received CRF alone that differed from the vehicle $(P=0.0142)$ and combined CRF and $\mathrm{CRF}_{1}$ antagonist conditions $(P=0.0457)$. G Diagram of the social affective behavior test (SAP) paradigm. Rats received insular cannula implants. On the test day, drug infusions were made $40 \mathrm{~min}$ before SAP tests consisting of a 5-min interaction with a naive and stressed samesex conspecific. The amount of time spent socially investigating each conspecific is recorded. $\mathbf{H}$ When tested under vehicle conditions with PN30 conspecifics, male rats $(n=19)$ exhibit greater exploration of the stressed rat $(P=0.0027)$; this pattern was blocked by the CRF 1 antagonist $(P=0.8293)$ supported by a significant interaction, $F_{\mathrm{CRF} 1 \text { antagonist } \times \text { Stress }}(1,18)=5.225, P=0.0346$. I Experimental male rats $(n=11)$ spent less time interacting with stressed PN50 adult conspecifics in the vehicle condition but this pattern was blocked by the CRF ${ }_{1}$ antagonist, $F_{\text {CRF1antagonist } \times \text { Stress }}(1,10)=6.133, P=0.0327$. Post hoc comparisons revealed a preference for more interaction with naive adults in vehicles $(P=0.0020)$ but no difference with the $\mathrm{CRF}_{1}$ antagonist $(P=0.5,50)$. J For comparison, time spent interacting with naive and stressed conspecifics from panels $\mathbf{H}$ and I was converted to a preference score (\% preference $=$ time investigating stressed conspecific/total investigation time $\times 100$ ). In vehicle conditions, experimental rats preferred interaction with stressed juveniles, but avoided stressed adults and $\mathrm{CRF}_{1}$ antagonist treatment appeared to reduce these preferences, $F_{\mathrm{Age}} \times$ Drug $(1,28)=11.30, P=0.0023$. When comparing juveniles, the percent preference for the stressed conspecific was significantly reduced by $\mathrm{CRF}_{1}$ antagonist $(P=0.0227)$. When comparing adults, although the $\mathrm{CRF}_{1}$ antagonist appeared to eliminate the preference for naive conspecifics, the Sidak-corrected post hoc test did not reach significance $(P=0.0768)$. K Cannula maps showing the placement of in-dwelling cannula across all experiments related to Fig. 3. Diagrams in panels $\mathbf{A}$ and G were created with BioRender.com.

conditioned freezing response [38], but CRF had no effect (Supplementary Results and Supplementary Fig. 3).

\section{$C B_{1}$ is necessary for the augmentation of excitatory neurotransmission and social behavior increases caused by CRF}

To better resolve the mechanism by which CRF alters insular excitatory/inhibitory tone we considered two possible mechanisms. First, CRF might directly alter GABAergic interneurons, GABA release, or $\mathrm{GABA}_{\mathrm{A}}$ kinetics. Second, CRF might indirectly modify GABA function via actions that begin with the $\mathrm{CRF}_{1}$ receptor on pyramidal neurons. While the former remains interesting, there are technical challenges with direct assessment of interneuron function in rats. Regarding the latter, depolarization and accumulation of intracellular calcium leads to the synthesis and retrograde release of endocannabinoids. Via action at the $\mathrm{G}_{\mathrm{i}}$ protein coupled presynaptic cannabinoid receptor $1\left(\mathrm{CB}_{1}\right)$, depolarization leads to the reduction in GABA release and the phenomenon of DSI [24]. Because CRF depolarized pyramidal neurons, we hypothesized that CRF might indirectly affect presynaptic GABA tone via endocannabinoids which led us to consider the role of $C_{1}$ in mediating effects of CRF. We utilized AM251 (2 $\mu \mathrm{M})$, a $C_{1}$ inverse agonist [39], in fEPSPs, elPSCs and social behavior in male rats. Coapplication of AM251 prevented CRF effects on synaptic transmission (Fig. 4A). In whole-cell recordings of elPSCs, CRF had no effect when administered with AM251 (Fig. 4B). As before, insular CRF injections increased social interaction with juvenile conspecifics. Interestingly, AM251 itself increased both fEPSP amplitude and social exploration which might be due to the blockade of $\mathrm{CB}_{1}$ receptors on both principle neurons and inhibitory interneurons resulting in a net excitatory modulation. AM251 (Fig. 4C) prevented insular CRF from increasing social investigation of a juvenile conspecific and brought the total amount of social interaction to vehicle levels (Fig. 4D). In SAP tests, AM251 prevented the formation of a preference for stressed juveniles (Fig. 4E) or unstressed adult conspecifics (Fig. 4F) indicating that, in addition to $\mathrm{CRF}_{1}, \mathrm{CB}_{1}$ is necessary for the evaluation of these socioemotional cues (Fig. 4G).

\section{Sex differences exist in $\mathrm{CRF}_{\mathbf{1}}$ and $\mathrm{CB}_{\mathbf{1}}$ mRNA expression and cellular distribution in the insular cortex}

The pattern of sex-specific effects of CRF on physiology and social behavior led us to hypothesize that sex differences exist in the amount or distribution of insular $\mathrm{CRF}_{1}$ and $\mathrm{CB}_{1}$. Using $\mathrm{qPCR}$ on insular cortex micro punches we found greater $C R_{1}$ mRNA in female rats compared to males (Fig. 5A). CRF (crh) and CRF type 2 receptor (crhr2) mRNAs were not detectable, which is consistent with prior reports $[40,41]$. To understand the functional sex differences we turned to RNAScope fluorescent in situ hybridization, to visualize and colocalize mRNAs of glutamatergic neurons (vGlut1), $\mathrm{CRF}_{1}$ (crhr1) and $\mathrm{CB}_{1}(\mathrm{cnr} 1)$ in insula sections from male and female adult rats (Fig. 5D, E). Males had more DAPI nuclei labeled with $\mathrm{CRF}_{1}$ and $\mathrm{CB}_{1}$ mRNA (Fig. 5B). Looking at putative glutamate neurons (vGlut1 positive cells, Fig. $5 \mathrm{C}$ ), there was a trend for greater $\mathrm{CRF}_{1}$ in males, but this did not reach significance $(P=0.067)$. However, in males we found more glutamate neurons colocalized with $\mathrm{CB}_{1}$ and more glutamate neurons colocalized with both $\mathrm{CRF}_{1}$ and $\mathrm{CB}_{1}$ mRNAs than females.

\section{DISCUSSION}

We investigated neural mechanisms by which social stress signals influence social behavior. We focused on the neuropeptide CRF, which is released during social interactions with stressed conspecifics [12], and the posterior insular cortex (IC), a structure needed for social affective behavior [29]. Electrophysiology, pharmacology, behavior and molecular experiments revealed a sex-specific role for CRF as a modulator of insular synaptic physiology and social behavior. In males only, CRF caused a reduction in presynaptic inhibitory tone, likely via release of retrograde endocannabinoids acting at presynaptic $\mathrm{CB}_{1}$ receptors. Behaviorally, insular CRF injections increased social interaction, and $\mathrm{CRF}_{1}$ and $\mathrm{CB}_{1}$ receptor antagonists both interfered with behavior in a SAP test. To understand the basis for the sex difference we used qPCR and in situ hybridization to describe the relative expression and cellular distribution of $\mathrm{CRF}_{1}$ and $\mathrm{CB}_{1}$ mRNAs. Although we found more overall $\mathrm{CRF}_{1}$ mRNA in females, we found that males had more $\mathrm{CRF}_{1}$ 
A

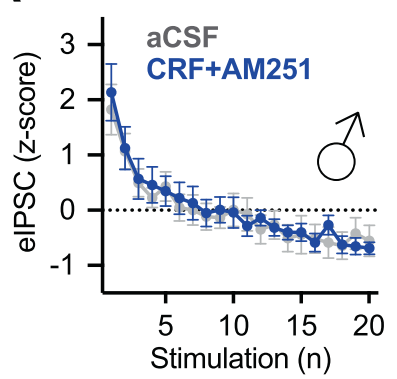

E

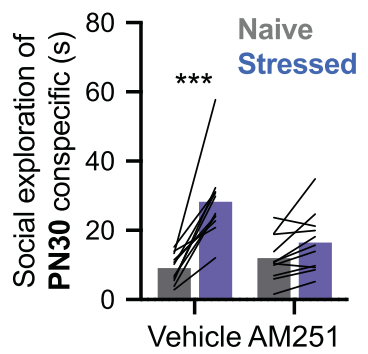

B

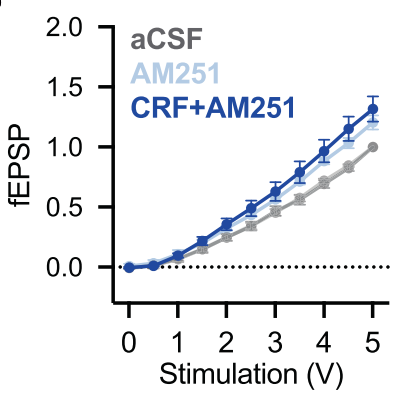

F

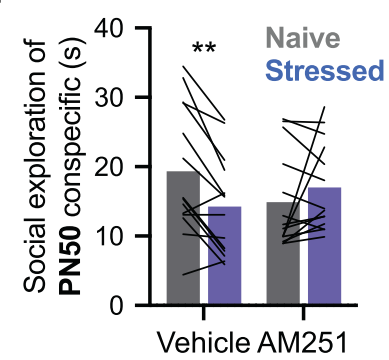

C

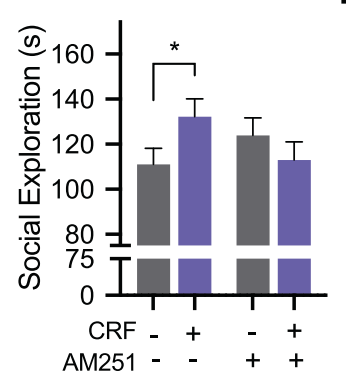

G

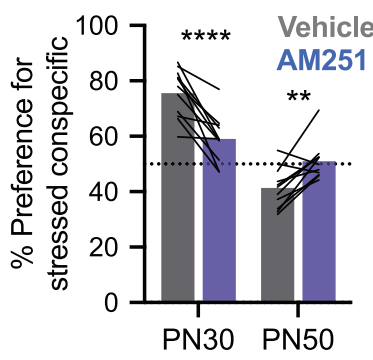

D
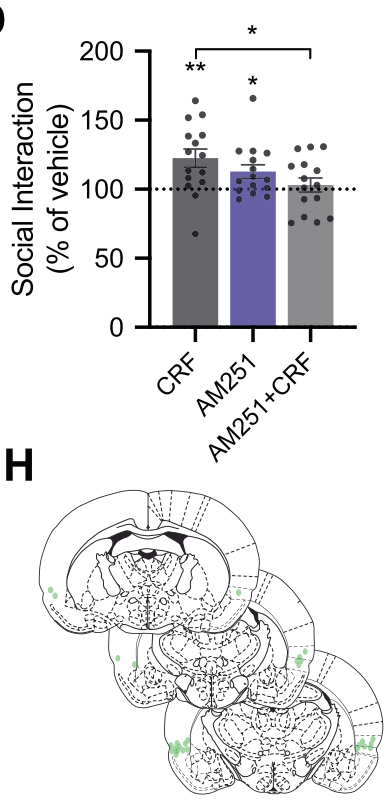

\section{I}

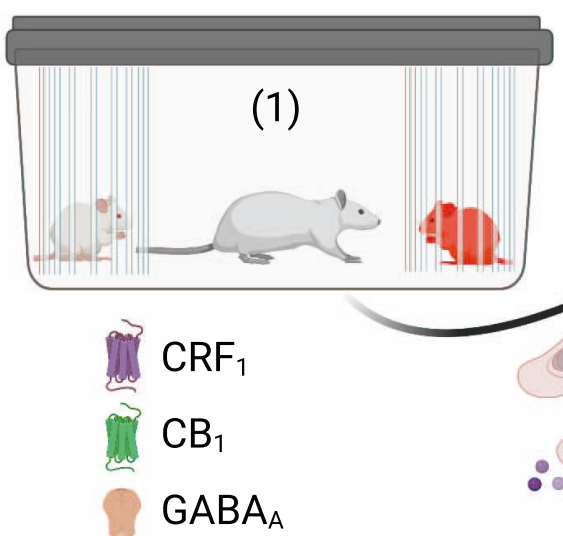

(2)

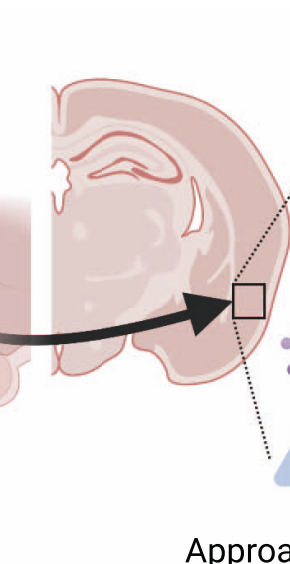

(5)

Approach (NAC) (6)

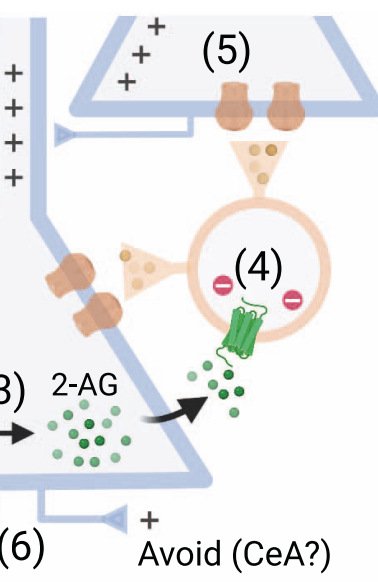

Fig. 4 Cannabinoid 1 receptor is necessary for the behavioral and synaptic effects of insular CRF. A fEPSPs recorded from insular cortex slices $(n=8)$ were insensitive to $300 \mathrm{nM}$ CRF when applied with $\mathrm{CB}_{1}$ receptor antagonist $\mathrm{AM} 251(2 \mu \mathrm{M}), F_{\text {Voltage }} \times$ Drug $(1,11)=2.992, P=0.0959$. B In voltage-clamp recordings of insular cortex pyramidal neurons $(n=9)$, AM251 prevented the inhibition of elPSCS previously caused by CRF $(50 \mathrm{nM})$ application, $F_{\text {Drug }}(1,8)=0.0157, P=0.9032$. C In a 5-min social interaction test with male rats $(n=15)$ CRF injected into the insular cortex increased exploration of juvenile conspecifics $(P=0.0270)$. CRF given in combination with AM251 did not increase social exploration, $F_{\mathrm{CRF} \times \mathrm{AM} 251}(1,14)=9.102, P=0.0092$. D For comparison, raw social interaction times from panel $\mathrm{C}$ are shown as percent of time relative to the no drug condition. CRF increased interaction (one-sample $t$-test compared to $100 \%, t(14)=3.422, P=0.0041, A M 251$ alone increased interaction, $t(14)=2.620, P=0.0202$, but CRF given with AM251 did not differ from vehicle levels, $t(14)=0.5935, P=0.5623$. Importantly, social interaction was greater with CRF alone than in combination with AM521, $(P=0.0110$, Sidak test after significant one-way ANOVA, $F(2$, $28)=3.705, P=0.0374)$. E In SAP tests with juveniles $(n=11)$, AM251 prevented the formation of a preference for stressed juvenile conspecifics, $F_{\text {Drug }} \times \operatorname{Stress}(1,9)=22.53, P=0.0010$, such that the preference for stressed juveniles present during vehicle testing $(P<0.0001)$ was eliminated during AM251 testing $(P=0.0940)$. F In SAP tests with adult conspecifics $(n=16)$, AM251 eliminated the preference of test rats for naive adult $F_{\text {Drug }} \times$ Stress $(1,13)=19.93, P=0.0006$. A significant preference for naive adults was present in vehicle test rats $(P=0.0013)$ that was not present in AM251 rats $(P=0.1691)$. G Percent preference for stressed conspecifics was significantly altered by a combination of AM251 treatment and age of conspecific $F_{\text {Age }} \times$ Drug $(1,20)=43.12, P<0.0001$. Specifically, the percent preference for stressed juveniles was significantly reduced $(P<0.0001)$ while the percent preference for stressed adults was significantly increased $(P=0.0054)$. $\mathbf{H}$ Cannula placements of all animals in the experiments contained in Fig. 4. I Summary of behavioral pharmacology. (1) Exposure to the stressed conspecific causes emotion transfer and release of CRF (purple) from the paraventricular nucleus of the hypothalamus. (2) CRF binds to principal neurons in the insular cortex leading to depolarization and (3) synthesis of endocannabinoids, such as 2-AG. (4) Endocannabinoids (green) bind to $\mathrm{CB}_{1}$ receptors on presynaptic GABAergic interneurons (orange) leading to hyperpolarization and suppression of local inhibition. (5) The loss of GABAergic inhibition permits greater excitatory synaptic transmission among principal neurons (6) whose output shapes social approach or avoidance by projections to nodes in the social decision-making network. Diagram created in BioRender.com. Bar graphs indicate mean with individual replicates, line graphs mean $( \pm \mathrm{SEM}) .{ }^{*} P<0.05,{ }^{* *} P<0.01,{ }^{* * *} P<0.001,{ }^{* * * *} P<0.0001$ (Sidak's tests). 
A

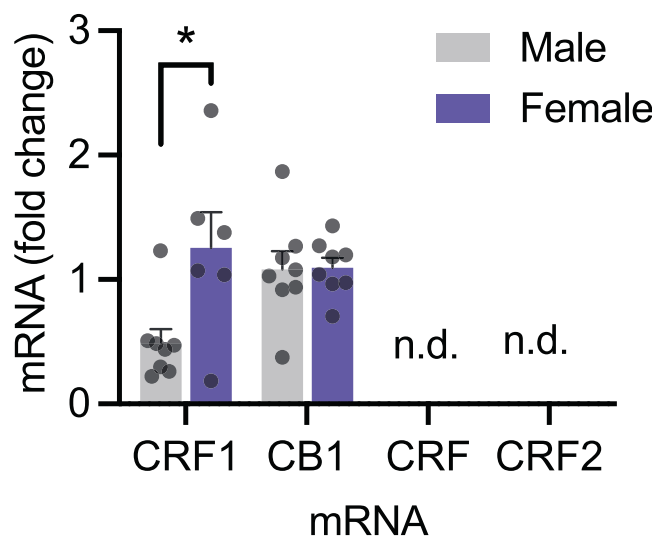

B

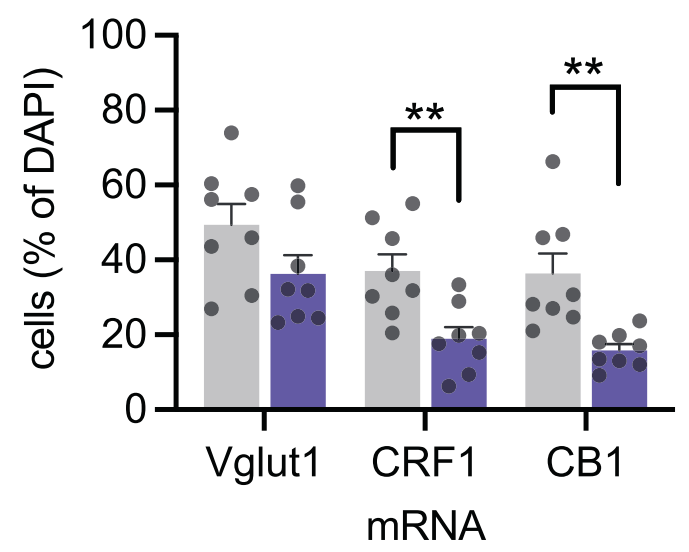

C

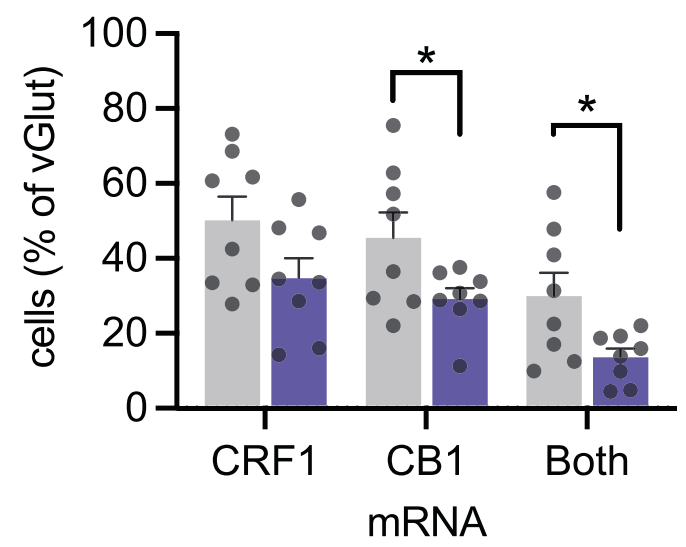

positive cells and increased $\mathrm{CRF}_{1}$ and $\mathrm{CB}_{1}$ colocalization on glutamate neurons. In sum, these results add to our understanding of CRF as a neuromodulator, integrate CRF into a social affective behavior process, and have important implications for understanding the neurobiology of social cognition.

The depolarizing effect of CRF on membrane potential is consistent with the $\mathrm{G}_{\mathrm{s}}$-protein signaling and CAMP modulation of cation channels [42]. However, the dampening effects of CRF on the $A P$, reduction of $A D P$ and the increase in rectification ratio suggest additional effects of CRF via modulation of ion channels

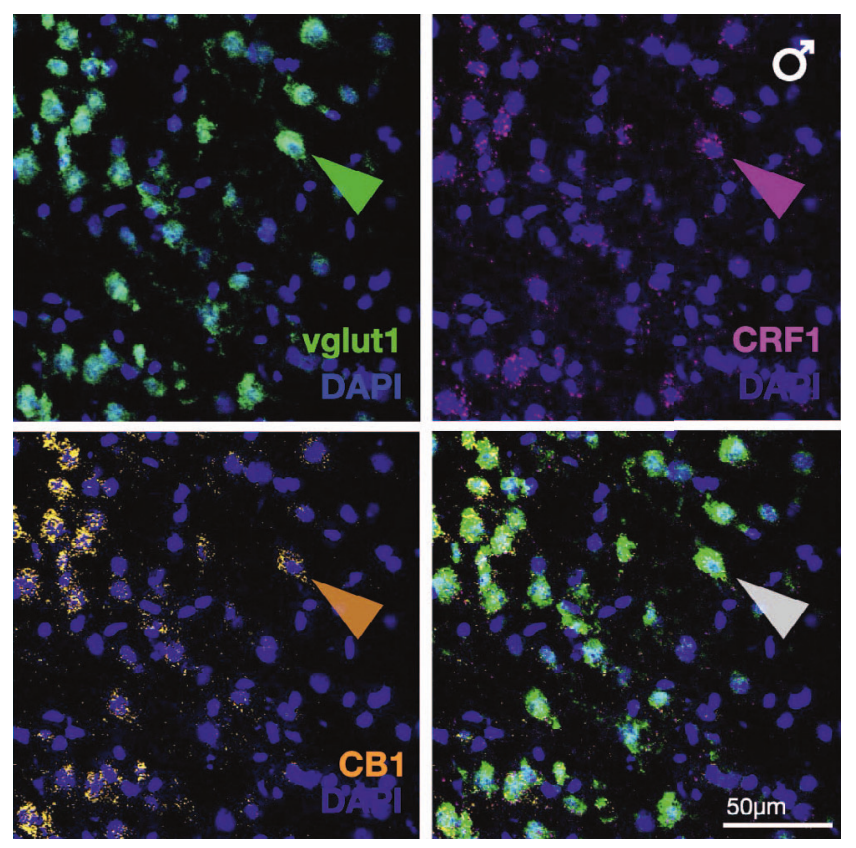

드
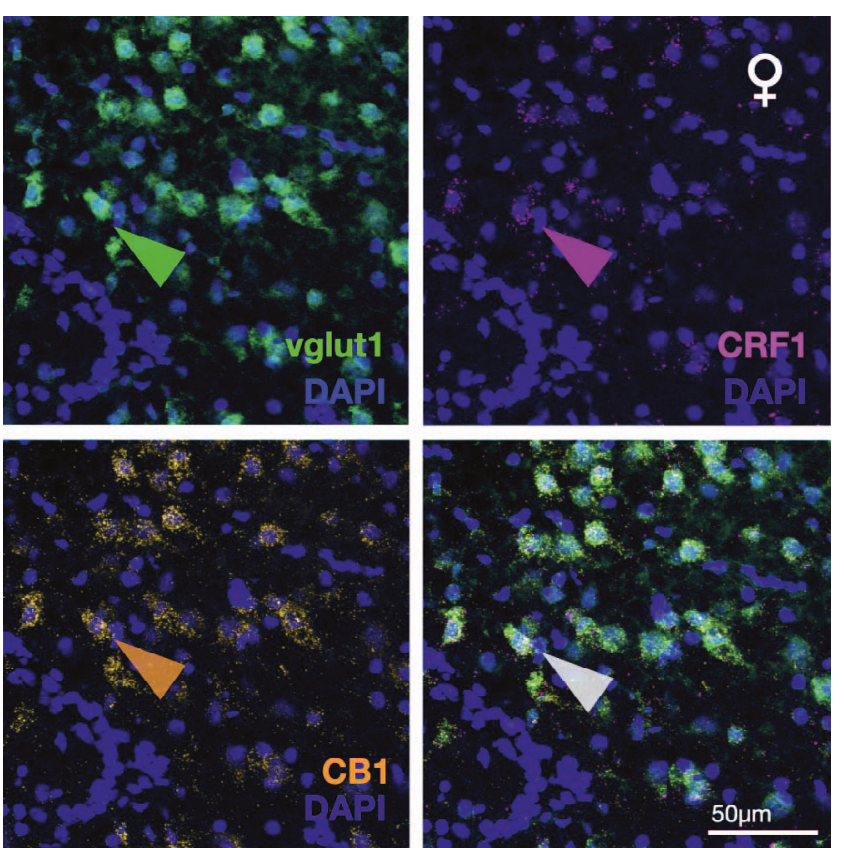

such as T-type voltage-gated calcium channels [43] or voltagegated potassium channels [35]. The most robust effect of CRF was depolarization of the membrane potential which we predicted would lead to augmentation of excitatory synaptic transmission. When looking at synaptic measures, however, sex-specific effects of CRF become clear. In males, CRF augmented fEPSPs in a doseand $\mathrm{CRF}_{1}$-dependent fashion. The synaptic effect of CRF also depended upon $G_{A B A_{A}}$ receptors, suggesting a more complex mechanism of action for CRF than direct modulation of principal neurons via $\mathrm{CRF}_{1}$. We further investigated this in eIPSCs as a 
Fig. 5 Cellular distribution of $\mathbf{C R F}_{\mathbf{1}}$ and $\mathrm{CB}_{\mathbf{1}}$ receptor $\mathbf{m R N A}$ in the insular cortex. $\mathrm{A} q \mathrm{qPR}$ analysis of relative $\mathrm{mRNA}$ expression revealed greater $\mathrm{CRF}_{1}$ mRNA in females compared to males $t(12)=2.728, P=0.183$, and equal $\mathrm{CB}_{1}$ mRNA across sexes $t(14)=0.090, P=0.929$. B RNAScope was performed for $\mathrm{CRF}_{1}, \mathrm{CB}_{1}$, and vglut1 mRNAs. Fluorescent grains were counted in the left and right hemispheres of the posterior insular cortex. The total number of cells was determined by counting DAPI nuclei in each hemisphere. Nuclei containing 3 or more fluorescent grains were considered mRNA expressing cells and shown as the \% of the total cells. The number of vglut1 cells was equal between sexes, but the portion of cells expressing $\mathrm{CRF}_{1} F_{\mathrm{Sex}}(1,14)=11.19, P=0.005$, or $\mathrm{CB}_{1}, \mathrm{~F}_{\mathrm{Sex}}(1,14)=13.07, P=0.003, \mathrm{mRNA}$ was approximately double in males compared to females. $C$ Looking at expression of $C_{R F}$ and $C_{1} B_{1} \mathrm{mRNA}_{1}$ in vglut 1 cells, shown as a percent of the total vglut1 cells per hemisphere, male rat sections contained more $\mathrm{CB}_{1}$ mRNA expressing vglut cells, and more vglut cells expressing both $\mathrm{CB}_{1}$ and $\left.\mathrm{CRF}_{1} \mathrm{mRNA}, F_{\mathrm{Sex}}(1,14)=4.489, P=0.044\right)$. The number of vglut cells expressing $\mathrm{CRF} 1 \mathrm{mRNA}$ was greater on average in males than females, but did not reach significance $F_{\text {Sex }}(1,14)=3.944, P=0.067$. In males, there were more vglut cells colocalized with both $C R F_{1}$ and $C B_{1}$, $F_{\text {Sex }}(1,14)=6.576, P=0.023$. D, E Representative digital photomicrographs of RNAScope in situ hybridization and fluorescent visualization of $\mathrm{DAPI}$ and vesicular glutamate transporter 1 (vglut1), $\mathrm{CRF}_{1}$ (crhr1), and $\mathrm{CB}_{1}$ (cn1r) mRNA from male (A) and female (rats) insular cortex coronal

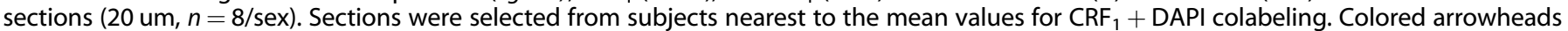
indicate cells with coexpression of all three mRNAs with DAPI. Bar graphs indicate mean $( \pm \mathrm{SEM})$ with individual replicates. ${ }^{*} P<0.05$, ${ }^{*} P<0.01$, ${ }^{* * *} P<0.001,{ }^{* * * *} P<0.0001$ (Sidak's tests).

measure of GABAergic tone and found a $\mathrm{CRF}_{1}$-dependent reduction in eIPSC amplitude in males, but not females. Because depolarization alone is sufficient to inhibit presynaptic GABAergic transmission via retrograde endocannabinoids and the $C_{1}$ receptor [24] we tested the dependence of CRF effects on $C_{1}$ and found that both the augmentation of fEPSPs and suppression of eIPSCs were prevented by pretreatment with a $\mathrm{CB}_{1}$ receptor inverse agonist. These results suggest that $\mathrm{CRF}$ action within the insula may begin with $\mathrm{CRF}_{1}$-mediated depolarization of pyramidal neurons that then release endocannabinoids which, in turn, cause suppression of presynaptic GABAergic neurons accounting for the increase in excitatory transmission in male insula (Fig. 4l). This mechanism of CRF action is present in the lateral habenula [44]. Similarly, oxytocin can also trigger endocannabinoid release increasing postsynaptic excitability [45]. This may indicate that insular control of social behavior by different neuromodulators, oxytocin [29] and CRF is driven by a convergent mechanism whereby $\mathrm{CB}_{1}$-dependent inhibition of presynaptic GABA leads to postsynaptic excitability. One possibility for how this occurs is DSI and, interestingly, experimentally induced endocannabinoidmediated DSI occurs after strong depolarization protocols [46], whereas here CRF led to depolarization of $\sim 4-7 \mathrm{mV}$. It is also possible that eCBs synthesis and release were a result of G-protein mediated effects including the release of intracellular calcium or protein kinase-dependent actions that may occur downstream of insular $\mathrm{CRF}_{1}$ receptors [44]. Thus, important goals of future work include determining if small, sustained depolarizations are sufficient to evoke $\mathrm{CB}_{1}$-dependent presynaptic inhibition, identify the molecular cascades linking CRF and endocannabinoids (such as modulation of endocannabinoid metabolism as in $[47,48]$ ), the type of presynaptic cells effected by endocannabinoids, the source of insular CRF, and the sex differences in these systems that result in male-specific effects.

Detecting socioemotional cues and using this information to inform whether to approach or avoid others is a vital aspect of social behavior. CRF receptors are distributed across many structures critical to social behavior [15] and the observer stress response, a form of emotion contagion, may be elementary to more complex social cognition that involves a distributed social affective behavior network [27]. Sterley et al. [9] observed that exposure to stressed conspecifics potentiated PVN CRF neurons. Here, insular injections of CRF increased social investigation of both juvenile and adult conspecifics, but only in male rats. In the SAP test, experimental rats typically prefer to interact with stressed juvenile conspecifics but avoid stressed adults [29, 33]. The $\mathrm{CRF}_{1}$ antagonist prevented this pattern suggesting that activation of the CRF acute stress response, as reported by Sterely et al., likely occurs in the experimental rat during the SAP test. The framework is that the decision to approach or avoid another involves assessment of the subject's core affect (e.g., "Am I in danger?") and social affective information about the social target (e.g., "Is the conspecific in danger?"). Avoidance occurs when the targets are adults, possibly because the subject experiences greater internal distress/danger as the adult targets could be communicating imminent environmental threat or pose a threat (e.g., aggression) themselves. Alternatively, when the targets are juveniles, there is less (or none) social threat and approach occurs, possibly because the signals given off by stressed juveniles are social attractants [49] or there are innate prosocial drives [50]. As this test is relatively new we have only examined a few additional circumstances but together they fit in this framework. First, the approach to the stressed adult occurs when the subjects are familiar [33] likely reflective of less subject anxiety due to familiarity. Second, another lab found that prior stress of the test subject led to social avoidance-interestingly also sensitive to manipulations of the peripheral stress system [51]. Third, adult rats avoid sick adults, a phenomenon that also requires insula [52]. Consistently, CRF mediates defensive responses to synthetic fox odor, a potent social stressor, by potentiation of prefrontal cortex excitatory synaptic transmission [26]. The current results suggest that CRF provides an organizing signal about the subject's core affect.

The CRF system is complex, comprising of many sex, brain region and cell type-specific differences and functional contributions to behavior. As such, while the finding that CRF in the insula acts in a sex-specific manner to augment social behavior and drive social affective behavior in males is novel, the fact that a sex difference exists is not surprising. Here we began to understand the molecular basis for the sex difference by quantifying the relative expression and cellular distribution of $\mathrm{CRF}_{1}$ and $\mathrm{CB}_{1}$ mRNAs. Interestingly, qPCR revealed a greater relative amount of insular $\mathrm{CRF}_{1}$ mRNA in females compared to males and no difference in relative $C_{1}$ expression between males and females, indicating that the synaptic and behavioral sex differences found here are not likely due to less available $\mathrm{CRF}_{1}$. These results contrast some prior reports that find greater $\mathrm{CRF}_{1}$ mRNA in prefrontal cortex of males [53] but it is difficult to generalize across regions as $\mathrm{CRF}_{1}$ receptor binding varies in sex-specific ways with female adult rats tending to have more binding than males [54]. Regarding cellular distribution, we found more $\mathrm{CRF}_{1}$ and $\mathrm{CB}_{1}$ mRNA containing nuclei and glutamatergic neurons in males compared to females. While it is important to note that these measures of $\mathrm{CRF}_{1}$ and $\mathrm{CB}_{1}$ mRNAs are nuclear and may not reflect the actual expression of the receptors on synaptic terminals arriving from sources afferent to the insula, the distribution does illuminate a mechanism for sex-specific effects. First, the male insula contained more $\mathrm{CRF}_{1}$ expressing glutamatergic neurons than females, providing a larger population of neurons to be depolarized. Notably, both males and females exhibited CRF-induced changes in intrinsic neuronal physiology suggesting that female insula neurons express sufficient $\mathrm{CRF}_{1}$ for modulation of intrinsic excitability. Sex differences in physiology 
emerged at the synaptic level and the combination of mRNA distribution and pharmacology results suggest that this is due to much higher $\mathrm{CB}_{1}$ expression in males (Fig. 5 and Ref. [55]), which were required for the CRF-mediated effects on excitatory transmission, modulation of inhibitory presynaptic tone and social behavior. Thus, in males, CRF leads to a $\mathrm{CRF}_{1}$-dependent release of eCBs that modulate presynaptic inhibition and behavior via $C B_{1}$ in males. Females may not have sufficient insular $\mathrm{CB}_{1}$ to complete this cascade of signals and so CRF does not alter synaptic efficacy or behavior. It remains possible that there are other sex differences including the distribution of these receptors within the cortical interneuron subtypes or the cellular signaling cascades involved, both of which are exciting and clinically relevant directions for future research.

Human neuroimaging studies implicate the insula in an impressive range of cognitive processes $[2,4,5,7,8,56]$, including emotion recognition [6], anticipatory fear and anxiety [46, 57, 58]. Acute stress increases insula activity and functional connectivity $[59,60]$ and trauma leads to lasting enhancement of processing within insula networks $[11,61]$. In response to threat, CRF likely contributes to organizing insula and broader networks to determine what responses are situationally appropriate and the current results encourage further investigation of insular CRF in the stress-related psychopathologies.

\section{REFERENCES}

1. Menon V, Uddin LQ. Saliency, switching, attention and control: a network model of insula function. Brain Struct Funct. 2010;214:655-67.

2. Seeley WW, Menon V, Schatzberg AF, Keller J, Glover GH, Kenna H, et al. Dissociable intrinsic connectivity networks for salience processing and executive control. J Neurosci J Soc Neurosci. 2007;27:2349-56.

3. Craig AD. How do you feel? Interoception: the sense of the physiological condition of the body. Nat Rev Neurosci. 2002;3:655-66.

4. Gogolla N. The insular cortex. Curr Biol. 2017;27:R580-R586.

5. Contreras $M$, Ceric F, Torrealba F. Inactivation of the interoceptive insula disrupts drug craving and malaise induced by lithium. Science. 2007;318:655-8.

6. Gu X, Hof PR, Friston KJ, Fan J. Anterior insular cortex and emotional awareness. J Comp Neurol. 2013;521:3371-88.

7. Lu C, Yang T, Zhao H, Zhang M, Meng F, Fu H, et al. Insular cortex is critical for the perception, modulation, and chronification of pain. Neurosci Bull. 2016;32:191-201.

8. Phelps EA, O'Connor KJ, Gatenby JC, Gore JC, Grillon C, Davis M. Activation of the left amygdala to a cognitive representation of fear. Nat Neurosci. 2001;4:437-41.

9. Klein AS, Dolensek N, Weiand C, Gogolla N. Fear balance is maintained by bodily feedback to the insular cortex in mice. Science. 2021;374:1010-5.

10. Gehrlach DA, Weiand C, Gaitanos TN, Cho E, Klein AS, Hennrich AA, et al. A wholebrain connectivity map of mouse insular cortex. ELife. 2020;9:e55585.

11. Peters SK, Dunlop K, Downar J. Cortico-striatal-thalamic loop circuits of the salience network: a central pathway in psychiatric disease and treatment. Front Syst Neurosci. 2016;10:104.

12. Sterley T-L, Baimoukhametova D, Füzesi T, Zurek AA, Daviu N, Rasiah NP, et al. Social transmission and buffering of synaptic changes after stress. Nat Neurosci. 2018;21:393-403.

13. Bangasser DA, Wiersielis KR. Sex differences in stress responses: a critical role for corticotropin-releasing factor. Horm Athens Greece. 2018;17:5-13.

14. Deussing JM, Chen A. The corticotropin-releasing factor family: physiology of the stress response. Physiol Rev. 2018;98:2225-86.

15. Hostetler CM, Ryabinin AE. The CRF system and social behavior: a review. Front Neurosci. 2013;7:92

16. Li C, Vaughan J, Sawchenko PE, Vale WW. Urocortin III-immunoreactive projections in rat brain: partial overlap with sites of type 2 corticotrophin-releasing factor receptor expression. J Neurosci J Soc Neurosci. 2002;22:991-1001.

17. Potter E, Sutton S, Donaldson C, Chen R, Perrin M, Lewis K, et al. Distribution of corticotropin-releasing factor receptor mRNA expression in the rat brain and pituitary. Proc Natl Acad Sci USA. 1994;91:8777-81.

18. Sánchez MM, Young LJ, Plotsky PM, Insel TR. Autoradiographic and in situ hybridization localization of corticotropin-releasing factor 1 and 2 receptors in nonhuman primate brain. J Comp Neurol. 1999;408:365-77.

19. Sawchenko PE, Swanson LW, Vale WW. Corticotropin-releasing factor: coexpression within distinct subsets of oxytocin-, vasopressin-, and neurotensinimmunoreactive neurons in the hypothalamus of the male rat. J Neurosci. $1984 ; 4: 1118-29$
20. Bernhardt BC, Singer T. The neural basis of empathy. Annu Rev Neurosci. 2012:35:1-23.

21. Thioux M, Keysers C. Empathy: shared circuits and their dysfunctions. Dialogues Clin Neurosci. 2010;12:546-52.

22. de Waal FBM, Preston SD. Mammalian empathy: behavioural manifestations and neural basis. Nat Rev Neurosci. 2017;18:498-509.

23. Sterley T-L, Bains JS. Social communication of affective states. Curr Opin Neurobiol. 2021;68:44-51.

24. Katona I, Freund TF. Multiple functions of endocannabinoid signaling in the brain. Annu Rev Neurosci. 2012;35:529-58.

25. Varodayan FP, Correia D, Kirson D, Khom S, Oleata CS, Luu G, et al. CRF modulates glutamate transmission in the central amygdala of naïve and ethanol-dependent rats. Neuropharmacology. 2017;125:418-28.

26. Hwa LS, Neira S, Pina MM, Pati D, Calloway R, Kash TL. Predator odor increases avoidance and glutamatergic synaptic transmission in the prelimbic cortex via corticotropin-releasing factor receptor 1 signaling. Neuropsychopharmacology. 2019;44:766-75.

27. Rogers-Carter MM, Christianson JP. An insular view of the social decision-making network. Neurosci Biobehav Rev. 2019;103:119-32.

28. Worley NB, Varela JA, Gaillardetz GP, Hill MN, Christianson JP. Monoacylglycerol lipase alpha inhibition alters prefrontal cortex excitability and blunts the consequences of traumatic stress in rat. Neuropharmacology. 2020;166:107964.

29. Rogers-Carter MM, Varela JA, Gribbons KB, Pierce AF, McGoey MT, Ritchey M, et al. Insular cortex mediates approach and avoidance responses to social affective stimuli. Nat Neurosci. 2018;21:404-14.

30. De Souza E, Perrin M, Insel T, Rivier J, Vale W, Kuhar M. Corticotropin-releasing factor receptors in rat forebrain: autoradiographic identification. Science. 1984;224:1449-51.

31. Sanchez MMS, Young LJ, Plotsky PM, Insel TR. Autoradiographic and in situ hybridization localization of corticotropin-releasing factor 1 and 2 receptors in nonhuman primate brain. J Comp Neurol. 1999;480:365-77.

32. Rogers-Carter MM, Djerdjaj A, Gribbons KB, Varela JA, Christianson JP. Insular cortex projections to nucleus accumbens core mediate social approach to stressed juvenile rats. J Neurosci J Soc Neurosci. 2019;39:8717-29.

33. Rogers-Carter MM, Djerdjaj A, Culp AR, Elbaz JA, Christianson JP. Familiarity modulates social approach toward stressed conspecifics in female rats. PLoS One. 2018;13:e0200971.

34. Chen VM, Foilb AR, Christianson JP. Inactivation of ventral hippocampus interfered with cued-fear acquisition but did not influence later recall or discrimination. Behav Brain Res. 2016;296:249-53.

35. Kratzer SMD, Mattusch CPD, Noll-Hussong MMD, Eder MPD, Kafitz KW, Metzger $\mathrm{MW}$, et al. Activation of $\mathrm{CRH}$ receptor type 1 expressed on glutamatergic neurons increases excitability of CA 1 pyramidal neurons by the modulation of voltagegated ion channels. Front Cell Neurosci. 2013;7:91.

36. Gogolla N, Takesian AE, Feng G, Fagiolini M, Hensch TK. Sensory integration in mouse insular cortex reflects GABA circuit maturation. Neuron. 2014;83:894-905.

37. Miura I, Sato M, Overton ETN, Kunori N, Nakai J, Kawamata T, et al. Encoding of social exploration by neural ensembles in the insular cortex. PLoS Biol. 2020;18: e3000584.

38. Foilb AR, Flyer-Adams JG, Maier SF, Christianson JP. Posterior insular cortex is necessary for conditioned inhibition of fear. Neurobiol Learn Mem. 2016;134:317-27.

39. Nicholson RA, Liao C, Zheng J, David LS, Coyne L, Errington AC, et al. Sodium channel inhibition by anandamide and synthetic cannabimimetics in brain. Brain Res. 2003;978:194-204.

40. Tan LA, Vaughan JM, Perrin $M H$, Rivier JE, Sawchenko PE. Distribution of corticotropin-releasing factor (CRF) receptor binding in the mouse brain using a new, high-affinity radioligand, [125 l]-PD-Sauvagine. J Comp Neurol. 2017;525:3840-64.

41. Van Pett K, Viau V, Bittencourt JC, Chan RK, Li HY, Arias C, et al. Distribution of mRNAs encoding CRF receptors in brain and pituitary of rat and mouse. J Comp Neurol. 2000;428:191-212.

42. Inanobe A, Kurachi Y. Membrane channels as integrators of G-protein-mediated signaling. Biochim Biophys Acta. 2014;1838:521-31.

43. Tao J, Hildebrand ME, Liao P, Liang MC, Tan G, Li S, et al. Activation of corticotropin-releasing factor receptor 1 selectively inhibits CaV3.2 T-type calcium channels. Mol Pharm. 2008;73:1596-609.

44. Authement ME, Langlois LD, Shepard RD, Browne CA, Lucki I, Kassis $\mathrm{H}$, et al. A role for corticotropin-releasing factor signaling in the lateral habenula and its modulation by early-life stress. Sci Signal. 2018;11:eaan6480.

45. Oliet SHR, Baimoukhametova DV, Piet R, Bains JS. Retrograde regulation of GABA transmission by the tonic release of oxytocin and endocannabinoids governs postsynaptic firing. J Neurosci. 2007;27:1325-33.

46. Patel S, Kingsley PJ, Mackie K, Marnett LJ, Winder DG. Repeated homotypic stress elevates 2-arachidonoylglycerol levels and enhances short-term endocannabinoid signaling at inhibitory synapses in basolateral amygdala. Neuropsychopharmacology. 2009;34:2699-709. 
47. Gray JM, Vecchiarelli HA, Morena M, Lee TTY, Hermanson DJ, Kim AB, et al. Corticotropin-releasing hormone drives anandamide hydrolysis in the amygdala to promote anxiety. J Neurosci. 2015;35:3879-92.

48. Natividad LA, Buczynski MW, Herman MA, Kirson D, Oleata CS, Irimia C, et al. Constitutive increases in corticotropin releasing factor and fatty acid amide hydrolase drive an anxious phenotype. Biol Psychiatry. 2017;82:500-10.

49. Kiyokawa Y. Social odors: alarm pheromones and social buffering. Cham: Springer; 2015. p. 47-65.

50. Meyza KZ, Bartal IB-A, Monfils MH, Panksepp JB, Knapska E. The roots of empathy: through the lens of rodent models. Neurosci Biobehav Rev. 2017;76:216-34.

51. Toyoshima M, Mitsui K, Yamada K. Prior stress experience modulates social preference for stressed conspecifics in male rats. Neurosci Lett. 2021;765:136253.

52. Rieger NS, Worley NB, Ng AJ, Christianson JP. Insular cortex modulates social avoidance of sick rats. Behav Brain Res. 2022;416:113541.

53. Daiwile AP, Jayanthi S, Cadet JL. Sex- and brain region-specific changes in gene expression in male and female rats as consequences of methamphetamine selfadministration and abstinence. Neuroscience. 2021;452:265-79.

54. Weathington JM, Hamki A, Cooke BM. Sex- and region-specific pubertal maturation of the corticotropin-releasing factor receptor system in the rat. J Comp Neurol. 2014;522:1284-98.

55. Liu X, Li X, Zhao G, Wang F, Wang L. Sexual dimorphic distribution of cannabinoid 1 receptor mRNA in adult C57BL/6J mice. J Comp Neurol. 2020;528:1986-99.

56. Kurth F, Zilles K, Fox PT, Laird AR, Eickhoff SB. A link between the systems: functional differentiation and integration within the human insula revealed by meta-analysis. Brain Struct Funct. 2010;214:519-34.

57. Paulus MP, Stein MB. An insular view of anxiety. Biol Psychiatry. 2006;60:383-7.

58. Shin LM, Liberzon I. The neurocircuitry of fear, stress, and anxiety disorders. Neuropsychopharmacology. 2010;35:169-91.

59. Szeszko PR, Yehuda R. Magnetic resonance imaging predictors of psychotherapy treatment response in post-traumatic stress disorder: a role for the salience network. Psychiatry Res. 2019;277:52-57.

60. Thomason ME, Hamilton JP, Gotlib IH. Stress-induced activation of the HPA axis predicts connectivity between subgenual cingulate and salience network during rest in adolescents. J Child Psychol Psychiatry. 2011;52:1026-34.

61. Yuan H, Phillips R, Wong CK, Zotev V, Misaki M, Wurfel B, et al. Tracking resting state connectivity dynamics in veterans with PTSD. Neurolmage Clin. 2018;19:260-70.

\section{ACKNOWLEDGEMENTS}

The authors wish to thank Dr Bret Judson, director of the Boston College Imaging Core, for training and assistance with all microscopy, Nancy McGilloway and Todd Gaines, administrators of the Boston College Animal Care Facility, for outstanding animal husbandry, Rahul Alturi, Benjamin Tramonte and Emma Fritsch for assistance with RNAscope, and Bridget Brady and Shanon Lee for help with MEA electrophysiology and behavioral tests.

\section{AUTHOR CONTRIBUTIONS}

Conceptualization: NSR, JAV, HCB, JPC; methodology: NSR, JAV, AJN, LG, JPC; investigation: NSR, JAV, AJN, LG, AD, JPC; writing (original draft): NSR, JPC; writing (revision and editing): NSR, JPC; funding acquisition: JPC.

\section{FUNDING}

Funding for this work was provided by the Boston College Undergraduate Research Fellowship, the Gianinno Family, and the National Institutes of Health Grants $\mathrm{MH} 119422$ and $\mathrm{MH} 109545$.

\section{COMPETING INTERESTS}

The authors declare no competing interests.

\section{ADDITIONAL INFORMATION}

Supplementary information The online version contains supplementary material available at https://doi.org/10.1038/s41386-022-01292-7.

Correspondence and requests for materials should be addressed to John P. Christianson.

Reprints and permission information is available at http://www.nature.com/ reprints

Publisher's note Springer Nature remains neutral with regard to jurisdictional claims in published maps and institutional affiliations.

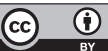

Open Access This article is licensed under a Creative Commons Attribution 4.0 International License, which permits use, sharing, adaptation, distribution and reproduction in any medium or format, as long as you give appropriate credit to the original author(s) and the source, provide a link to the Creative Commons license, and indicate if changes were made. The images or other third party material in this article are included in the article's Creative Commons license, unless indicated otherwise in a credit line to the material. If material is not included in the article's Creative Commons license and your intended use is not permitted by statutory regulation or exceeds the permitted use, you will need to obtain permission directly from the copyright holder. To view a copy of this license, visit http://creativecommons. org/licenses/by/4.0/.

(c) The Author(s) 2022 